\title{
Soil-plant-atmosphere interactions: structure, function, and predictive scaling for climate change mitigation
}

\author{
Lucas C. R. Silva ( $)$ Hans Lambers
}

Received: 21 August 2019 / Accepted: 7 January 2020 / Published online: 10 February 2020

(C) Springer Nature Switzerland AG 2020

\begin{abstract}
Background It is well established that the functioning of terrestrial ecosystems depends on biophysical and biogeochemical feedbacks occurring at the soil-plant-atmosphere (SPA) interface. However, dynamic biophysical and biogeochemical processes that operate at local scales are seldom studied in conjunction with structural ecosystem properties that arise from broad environmental constraints. As a result, the effect of SPA interactions on how ecosystems respond to, and exert influence on, the global environment remains difficult to predict.

Scope We review recent findings that link structural and functional SPA interactions and evaluate their potential for predicting ecosystem responses to chronic environmental pressures. Specifically, we propose a quantitative framework for the integrated analysis of three major
\end{abstract}

Responsible Editor: Alexia Stokes.

\section{C. R. Silva $(\bowtie)$}

Environmetal Studies Program, Department of Geography, Institute of Ecology \& Evolution, University of Oregon, Eugene, OR 97403, USA

e-mail:

\section{H. Lambers}

School of Biological Sciences and Institute of Agriculture, The University of Western Australia, Perth, WA 6009, Australia

\section{H. Lambers}

Key Laboratory of Plant-Soil Interactions, Ministry of Education, Beijing Key Laboratory of Biodiversity and Organic Farming, College of Resources and Environmental Sciences, China Agricultural University, 100193 Beijing, People's Republic of China plant functional groups (evergreen conifers, broadleaf deciduous, and understory shrubs) and their distinct mycorrhizal symbionts under rising levels of carbon dioxide, changing climate, and disturbance regime. First, we explain how symbiotic and competitive strategies involving plants and soil microorganisms influence scale-free patterns of carbon, nutrient, and water use from individual organisms to landscapes. We then focus on the relationship between those patterns and structural traits such as specific leaf area, leaf area index, and soil physical and chemical properties that constrain root connectivity and canopy gas exchange. Finally, we use those relationships to predict how changes in ecosystem structure may affect processes that are important for climate stability.

Conclusions On the basis of emerging ecological theory and empirical biophysical and biogeochemical knowledge, we propose ten interpretive hypotheses that serve as a primary set of hierarchical relationships (or scaling rules), by which local SPA interactions can be spatially and temporally aggregated to inform broad climate change mitigation efforts. To this end, we provide a series of numerical formulations that simplify the net outcome of complex SPA interactions as a first step towards anticipating shifts in terrestrial carbon, water, and nutrient cycles.

Keywords Carbon-water relations $\cdot$ Emerging properties · Numerical modeling · Soil-plant-microbe feedbacks · Resource limitation · Symbiosis ·

Spatiotemporal scaling 


\begin{tabular}{|c|c|}
\hline \multicolumn{2}{|c|}{ Abbreviations } \\
\hline A & photosynthesis \\
\hline AG & aboveground \\
\hline $\mathrm{AM}$ & arbuscular mycorrhizae \\
\hline BG & belowground \\
\hline $\mathrm{C}_{\mathrm{a}}$ & atmospheric $\mathrm{CO}_{2}$ \\
\hline $\mathrm{C}_{\mathrm{bg}}$ & total amount of carbon invested belowground \\
\hline $\mathrm{C}_{\mathrm{i}}$ & intercellular $\mathrm{CO}_{2}$ \\
\hline $\mathrm{C}_{\text {resp }}$ & heterotrophic respiration \\
\hline $\mathrm{C}_{\text {root }}$ & carbon allocated to root growth \\
\hline $\mathrm{C}_{\text {trans }}$ & carbon transferred from roots to symbionts \\
\hline $\mathrm{D}$ & solute dispersion coefficient \\
\hline$\delta^{13} \mathrm{C}$ & stable carbon isotope ratio \\
\hline$\delta \mathrm{D}$ & stable hydrogen isotope ratio \\
\hline$\delta^{18} \mathrm{O}$ & stable oxygen isotope ratios \\
\hline EM & ectomycorrhizae \\
\hline ET & evapotranspiration \\
\hline GPP & gross primary productivity \\
\hline$g_{s}$ & stomatal conductance \\
\hline $\mathrm{k}_{\mathrm{w}}$ & relative permeability of the soil \\
\hline K & hydraulic conductivity \\
\hline LAI & leaf area intex \\
\hline $\mathrm{N}$ & nitrogen \\
\hline NM & nonmycorrhizal \\
\hline$\eta$ & soil porosity \\
\hline $\mathrm{P}$ & phosphorus \\
\hline PM & parent materials \\
\hline PE & pedogenic energy \\
\hline $\mathrm{q}$ & connectivity of root-fungal networks \\
\hline $\mathrm{R}_{\mathrm{ac}}$ & resource acquisition \\
\hline $\mathrm{R}_{\mathrm{sp}}$ & $\begin{array}{l}\text { species-specific level of resource needed to } \\
\text { ensure survival }\end{array}$ \\
\hline s & soil saturation \\
\hline SLA & specific leaf area \\
\hline $\mathrm{t}$ & time \\
\hline $\mathrm{T}$ & transpiration \\
\hline$\theta$ & rate of resource uptake \\
\hline WUE & water-use efficiency \\
\hline NUE & nutrient-use efficiency \\
\hline$\omega$ & water-holding capacity \\
\hline$x$ & rate of water loss via ET \\
\hline$\psi$ & water potential \\
\hline$\sigma$ & return on carbon investme \\
\hline
\end{tabular}

\section{Introduction}

For thousands of years, the connection between soils, plants, and the atmosphere has captured people's imagination. We know this, because the origin of civilization can be traced back to our ancestors' recognition of species distribution patterns and their edapho-climatic domains, which guided the engineered expansion of useful plants and animals upon which we rely today. It is, therefore, not surprising that processes occurring at the soil-plant-atmosphere (SPA) interface became subject of inquiry long before the establishment of modern scientific methods. For example, natural philosophers of the eighteenth century made considerable efforts to characterize the structure and function of interacting SPA components through systematic observation, albeit depicted in poetic fashion, as in Johann von Goethe's The metamorphosis of plants (1790) - "Swells upward, trusting to the gentle dew ... The infinite freedom of the growing leaf ... Gently directing even higher perfection, Narrow the vessels, moderate the sap ... In careful number or in wild profusion ..." - or in Erasmus Darwin's (Charles' grandfather) The botanic garden (1791) - "Clasp in your airy arms the aspiring Plume ... Swell the green cup, and tint the flower with gold; While in bright veins the silvery Sap ascends ... While, spread in air, the leaves respiring play, Or drink the golden quintessence of day." Much has been learned since then, but the study of SPA interactions is still a research frontier, one that has the potential to transform our understanding of nature and ability to build a sustainable future.

For well over a century, SPA interactions have been studied from the perspective of a wide range of scientific disciplines, from chemistry to molecular biology, and from the rhizosphere to ecosystems (Hinsinger and Marschner 2006). A foundation for the quantitative analysis of SPA interactions was established in the 1960s (Philip 1966). In its most recognizable form, the term SPA “continuum" has since been used to describe movement of water from the soil through plants and into the air (Novák 2012). More recently, the notion of a soilto-atmosphere continuum was revised to include mass flow in the opposite direction, i.e. from the air through plants and into the soil (Johnstone and Dawson 2010; Eller et al. 2013; Earles et al. 2016). We now know that the exchange of mass and energy at the SPA interface affects climate and atmospheric composition from local to global scales (Baldocchi 2014; Brantley et al. 2017; 
Berhe et al. 2018). Progress in SPA understanding has been marked by the development of mathematical representations of mass and energy balances in the first general circulation models of the 1970s, and turbulent canopy fluxes in the 1990s which culminated in recent models that combine biophysical and biogeochemical forces acting on the Earth system (Bonan et al. 2014; Bonan 2015). Current models are used to address a wide range of environmental issues, from climate-change mitigation and adaptation policies to land - use regulations for sustainable food production. For example, SPA interactions are the focus of agricultural as well as ecological studies of global environmental change, greenhouse gas emissions, and carbon sequestration across biomes (e.g., Verhoeven et al. 2019; Bauters et al. 2019; Seitz et al. 2019). This trend is reflected in publication metrics, which show a tipping point in the early 2000's when $>60 \%$ of the top 100 most highlycited papers that mentioned "soils" also emphasized some aspect of SPA-mediated carbon dynamics (Lambers et al. 2007). However, there is little agreement about how ongoing changes in SPA structure and function will affect the costs and benefits of climate change mitigation efforts at scales that matter for policy and management going forward.

Despite growing interest in SPA interactions, the impacts of global environmental change on terrestrial ecosystems is poorly constrained with major discrepancies between predicted and measured scenarios for past and current transformation of terrestrial ecosystems under climate change (Nolan et al. 2018). In particular, empirical measurements and models diverge due to difficulties in representing ecological responses to changes in climate, rising $\mathrm{CO}_{2}$ levels, disturbance, and resource limitation in a single framework (Tharammal et al. 2019). Foremost among issues to be addressed, is a need for quantitative approaches that link the structure of plant and soil microbial communities with biophysical and biogeochemical processes to predict changes in ecosystem function (e.g. carbon, water, and nutrient cycling). Gaps in understanding hindering progress in this field stem from the fact that most ecological knowledge gathered to date comes from plot level measurements (Fig. 1a) or from unreplicated or infrequently replicated studies (Fig. 1b). Such a spatially and temporally constrained view is insufficient to address policy and management challenges that arise from global environmental change. For example, agriculture and forestry involve management plans that attempt to push the limits of carbon-water-nutrient tradeoffs by reducing competition for soil resources assuming steady climate and growing seasons, at no realized carbon costs, for decades to come (Amundson et al. 2015; Liles et al. 2019). This is problematic because managed landscapes typically store less carbon and use more water and nutrients than unmanaged landscapes (Franklin and Norman Johnson 2014; Perry and Jones 2017). Moreover, management can amplify the impact of disturbances driven by climate (Stevens et al. 2016; Brice et al. 2019), with significant consequences for ecological resilience to warming and drought stress (Hallema et al. 2018). It is therefore clear that a new approach is needed to inform policy and management for climate change mitigation.

We propose an approach that combines ecological theory with empirical biophysical and biogeochemical knowledge of SPA-mediated processes. Ecological interactions in general, and in particular those involving plants and soil microorganisms, influence competitive or facilitative processes that shape how ecosystems respond to climatic and other forms of environmental change. Our approach focuses on locally controlled SPA-mediated tradeoffs in carbon-waternutrient exchange, which scale to ecosystems and vary predictably in response to compounding stressors. This approach differs from models that rely primarily on correlative analyses of vegetation cover and temperature, which do not adequately represent SPA feedbacks. For example, recent progress in dynamic ecosystem modeling provides a useful foundation for estimating changes in carbon, water, and nutrient cycling functions at the SPA interface from changes in vegetation structure (Higgins 2017), but there remains a problem of integration and prediction across scales. In the following sections, we provide a summary of recent discoveries that can be used to improve numerical and interpretative prediction of SPA-mediated carbonwater-nutrient tradeoffs from molecules to landscapes (Fig. 1c). Our goal is to propose an integrative framework that we hope will accelerate convergence in as-of-yet disparate research frontiers to better inform climate change mitigation efforts.

\section{The problem of pattern and scale}

The problem of pattern and scale has long been recognized as "the key to prediction and understanding" in ecology (Levin 1992). It remains a challenge for scientists and policy makers owing to difficulties in scaling 


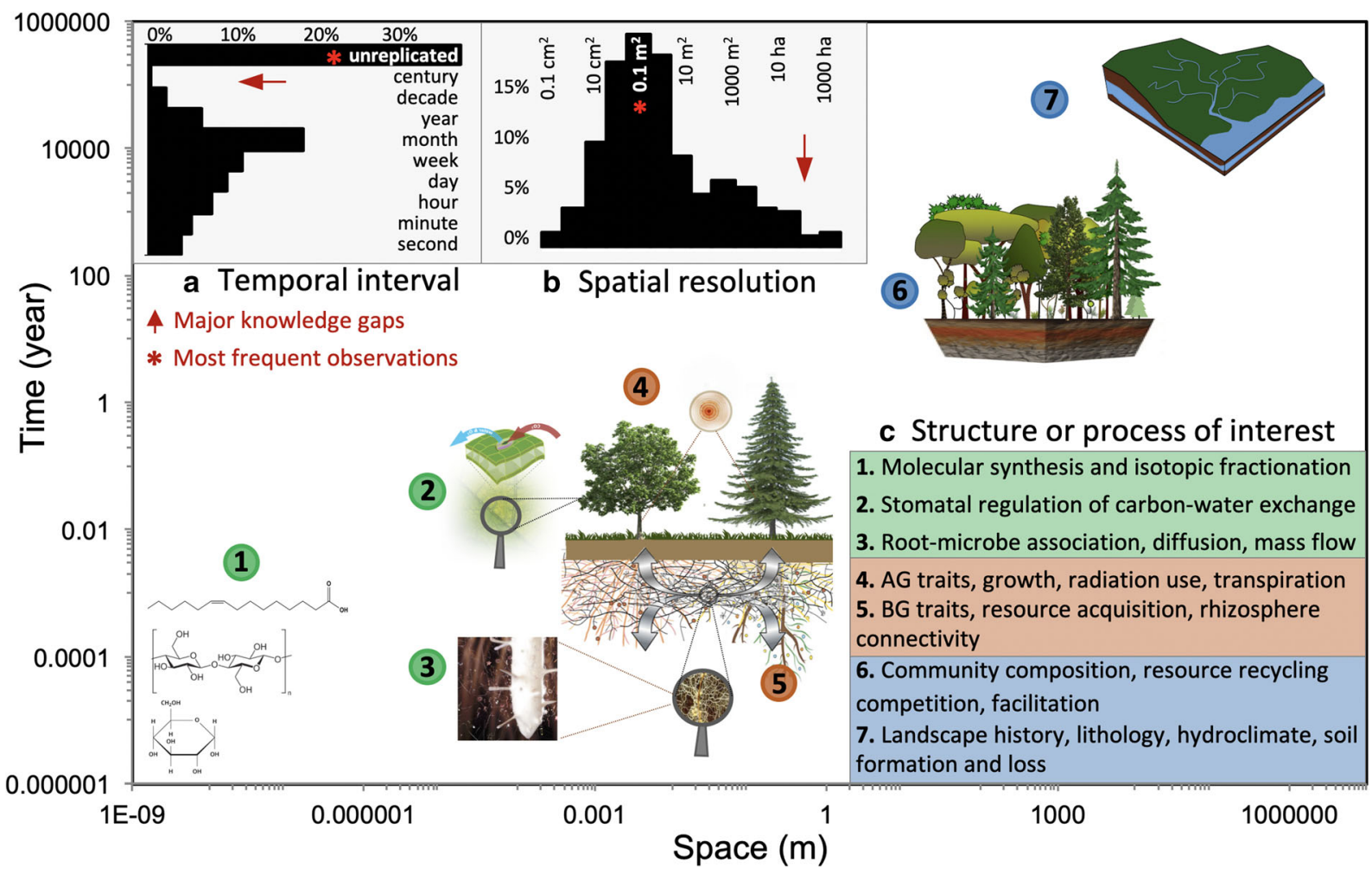

Fig. 1 Insets: The spatial and temporal domains of modern ecology showing frequencies of temporal (a) and spatial (b) scales of observations. Red arrows indicate major knowledge gaps and * indicates most frequent observations at "plot" and "unreplicated" levels; i.e. studies of $\leq 1$ day of duration (Estes et al. 2018). Main plot: Log-linear representation of approximate space and time scales within which SPA structures and processes of interest (c) operate at the scale of: (1) molecules (glucose, cellulose, lipids) whose isotope ratios reflect physiological stress (Sperling et al. 2017; Maxwell et al. 2018b); (2) stomata, which regulate leaf carbon-water relations and ecophysiological performance (Medlyn et al. 2017; Silva et al. 2015a); (3) root surface, myceli$\mathrm{um}$, and bacteria that influence nutrient acquisition and resource transfer (Jerszurki et al. 2017; Averill et al. 2019; Bomfim et al.

2019); (4) Aboveground (AG) traits that affect physiological performance, competition for light, and gas exchange (Baldocchi et al. 2018; Silva \& Anand, 2013; Silva et al. 2013a); (5) Belowground (BG) traits that control competition for water and nutrients and net resource flows in the soil (Lambers et al. 2008; Silva et al. 2013b, 2015b); (6) community composition and facilitative interactions that shape ecosystem structure, recycling of resources, and response to disturbance (Hoffmann et al. 2012; Rossatto et al. 2012; Franco et al. 2014; Paiva et al. 2016); (7) landscape history shaped by geological and climatological processes that form pedogenic gradients that constrain ecosystem distribution and function (Wortham et al. 2017; O'Geen et al. 2018; Ward et al. 2019; Hayes et al. 2019)

up the effect of ecological interactions, which are predominantly measured at small spatiotemporal scales i.e. at intervals ranging from days to months (Fig. 1a) and at the plot level (Fig. 1b). A coherent picture emerging from empirical research at macro- and micro-levels of ecological organization points to the integration " $o b$ servational and experimental datasets spanning multiple geographical scales" (Michaletz et al. 2018) as a path for predicting "inevitable emergent properties" of an ecosystem (Louca et al. 2018). This view is consistent with resilience theory, which proposes the study of interactions between small- and large-scale processes as

a means to predict the resilience of complex social and ecological systems to a wide gamut of environmental pressures (Folke et al. 2004; Gunderson and Holling 2002; Gunderson et al. 2017).

In organismal biology, allometric and stoichiometric properties - i.e. the relationship between size and anatomy of organisms and the proportions in which elements change as they move through them - provides the basis for scaling rules that predictively connect form and function. For example, a scalefree relationship exists between the life span and average metabolic rates of major groups of plants 
and animals, spanning several orders of magnitude in mass and size (Enquist 2002; Brown et al. 2004; Elser et al. 2010). Biological scaling has also been used to predict the functioning of ecosystems from morphological properties of dominant plant species (Boyce and Lee 2010) or from changes in species composition in response to climate fluctuations (Enquist et al. 2015, 2017). In physiological ecology, the relationship between the essential function primary productivity and foliar nutrient concentration can be inferred from leaf morphology as a traitdependent tradeoff involving growth form and nutrient use, termed the leaf economic spectrum, scales with foliar area, mass, and life span (Wright et al. 2004).

Beyond nutrients, the dependency of primary productivity on water use and transpiration is well documented for open grasslands (Valentini et al. 1995) as well as for closed-canopy forests (Chen and Coughenour 2004). Notably, the same morphological and functional links that characterize the leaf economic spectrum, ranging from that of short-lived leaves with high photosynthetic capacity per leaf mass to long-lived leaves with low massbased carbon assimilation rates, make leaf traits valid predictors for stomatal regulation of water loss via transpiration (Kröber et al. 2015). For landscapes containing vegetation mosaics, where species and ecosystems of varying structures co-exist, a combination of species traits (e.g., specific leaf area SLA) and ecosystem cover (e.g., leaf area index LAI) data allows leaf-to-canopy upscaling of photosynthesis and transpiration (Sprintsin et al. 2012). At regional to global scales, process-based models rely on those relationships to explain the strong spatial correlation between gross primary productivity (GPP) and water balance of terrestrial biomes (Beer et al. 2010). In other words, the same biophysical and biogeochemical forces that drive the fluxes of mass and energy at the local SPA interface also operate at the Earth system scale.

In summary, biological structure and function can be used in the development and calibration of scaling rules that identify the types of tradeoffs that govern ecological interactions by determining which of the physical and/or chemical constraints encountered by organisms are most likely to affect their growth and behavior (Kempes et al. 2019). As the external environment changes over time, the scalability of biological processes determines the resilience of interacting organisms such that those same scaling rules can be used to infer emergent properties of dynamic natural or human-engineered systems (West 2017). In the particular case of SPA interactions, the theoretical basis for such an integration of scaling approaches is robust, and so is the empirical knowledge gathered for centuries pertaining to the causal linkages between plants and soil microbial traits. For example, soil microbial processes are also mechanistically linked to variation in plant morphological and functional traits that influence the rates of organic matter deposition, decomposition, and nutrient cycling (Buzzard et al. 2019). What follows, is an attempt at advancing a unified framework that connects those and other well known SPA interactions at different levels of ecological organization for which mechanistic relationships can be derived (Fig. 1c).

\section{Towards a new paradigm: Simplifying complexity at the SPA interface}

The current ecological paradigm that describes biotic SPA interactions occurring below ground postulates that plant-microbe networks function as a "biological market" that favors the most beneficial cooperative partnerships (e.g., Kiers et al. 2011; Fellbaum et al. 2014); however, mutually beneficial transfer of limiting soil resources is only found in a subset of symbionts under particular conditions, whereas amplified competition is a more common observation (Weremijewicz et al. 2016). Almost all terrestrial plants form symbiotic associations with mycorrhizal fungi. It is estimated that 10 to $30 \%$ of the photosynthetic carbon produced by those plants is used to build root-fungal networks in exchange for up to $90 \%$ of their nutrient requirements (van der Heijden et al. 2015). Depending on the degree of nutrient and water limitation, coordinated responses in leaf gas exchange and nutrient uptake can occur among individuals whose rhizospheres are linked in common mycorrhizal networks (Gorzelak et al. 2015). Rhizosphere connections in such networks can function as "hubs" that effectively "even out" resource availability under environmental stress (Simard 2009), such that the balance between competitive to mutualistic associations at 
the SPA interface is expected to change the "terms of trade" between energy inputs and the return on carbon investment (Lambers et al. 2015). Rapid (i.e. days to weeks) short- and long-distance (i.e. centimeters to tens of meters) transfer of resources can occur in root-mycorrhizal networks via advective mass flow as well as active transport and diffusion through cell growth (Simard et al. 2012) as plant and microbial communities respond in concert to intermittent disturbances (e.g., fire and biomass removal; Song et al. 2015) or chronic stress (e.g., drought and climate warming; Bingham and Simard 2012). Thus, bidirectional movement of carbon, nitrogen, and mineral elements are expected due to sink-source strength gradients between plants and microbes which either facilitate mutualism or amplify competition. Notable examples include preferential allocation of resources to large fast-transpiring plants (Song et al. 2015; Weremijewicz et al. 2016), which can also result in stoichiometric differentials between plant organs and the soil matrix (Qiao et al. 2014; Winsome et al. 2017).

The extent to which plants support symbionts at the expense of their own carbon demands (a microbe-centric view) or root-fungi connections function simply as channels through which water and nutrients flow (a plant-centric view) is difficult to generalize. Empirical data exist to support both views, which embody a centuries-old debate between structuralists and functionalists (e.g., Goethe vs Darwin). To reconcile those opposing views, we propose that interactions between species functional traits and pedogenic gradients can be used to infer the magnitude and direction of resource exchange at the SPA interface in a predictable way that is neither plant- nor microbe-centric. For the purposes of prediction, scale-free tradeoffs between resource-acquisition efficiency and productivity can be adopted from from existing data. For example, a recent analysis of 2940 woody plant species show that mycorrhizal plants differ systematically in nitrogen $(\mathrm{N})$ and phosphorus $(\mathrm{P})$ use strategies (Averill et al. 2019), where ectomycorrhizal (EM) plant species are more conservative than arbuscular mycorrhizal (AM) species for the use of both elements. Those authors also found that the observed differences in mycorrhizal association were apparent in aboveground (AG) and belowground (BG) parameters even after controlling for evolutionary tradeoffs that favors dominance of deciduous or evergreen species across biomes. Evolutionary tradeoffs connect biological form and function across multiple levels of ecological organization including biophysical and biogeochemical SPA interactions (Messier et al. 2018) such that trends in plant and microbe composition and function can be predicted from pedogenic data. For example, changes in the relative dominance of symbiotic or asymbiotic organisms can be aggregated over space and time, based on the stage of soil formation (Doetterl et al. 2018). This is possible because mineral soil age - or the residence time of weathered secondary minerals since detachment from the original bedrock (Almond et al. 2007; Roering et al. 2007; Lindeburg et al. 2013) - dictates different modes of resource acquisition, or restrictions that favor certain resource-acquisition strategies (Fig. 2a), as a direct result of differences in the overall pool of available nutrients and water (Fig. 2b).

To simplify and scale SPA interactions, it would serve us well to combine multiple sources of empirical evidence that show how pedogenic thresholds (i.e. marked differences in soil physical and chemical properties) constrain spatiotemporal variation in functional diversity and resource use. For example, time-integrated energy input is the single most important predictor of plant functional diversity across terrestrial biomes (Fine 2015). At the same time, the functional diversity of soil microbes is governed by pedogenic energy inputs delineated by lithological, climatic, and ecological gradients across landscapes (Rasmussen and Tabor 2007). At early stages of soil development, plant cover is incipient and $\mathrm{N}$-fixing bacteria cyanobacteria and archaea tend to dominate (Fig. 2a). As soil develops, plant cover and biodiversity increase and so does biological $\mathrm{N}$ fixation and soil $\mathrm{N}$ concentration (Fig. 2b). In older soils, primary productivity becomes increasingly limited by mineral elements such as $\mathrm{P}$ and plants that rely on AM networks tend to be replaced by those that rely on EM networks. In AM- and EM-dominated systems, rootmycorrhizal associations allow short- and longdistance (i.e., millimeters to tens of meters) transfer of carbon and nutrients through advection and diffusion (Heaton et al. 2012). Aqueous solution cannot be compressed in such networks; thus, maintenance of AG structure and productivity depends on BG connectivity which requires large amounts of water to be stored between the sites of uptake and transpiration 
Fig. 2 Changes in soil properties with soil age spanning a few hundred to $\sim 2$ million years of soil development: (a) Resource acquisition and species diversity. Thicker wedges mean greater relative abundance of resourceacquisition strategies (Lambers et al. 2008), with decreasing trends represented by green wedges and increasing trends represented by yellow wedges. Dashed lines indicate decreasing trends in the total number of soil bacteria, which often accompanies soil acidification (Delgado-Baquerizo et al. 2018), and the total numbers of plant species, which tends to increase from young to old soils (Zemunik et al. 2015, 2016). (b) Soil physicochemical properties and their typical changes over time as a function of pedogenesis. Waterholding capacity adapted from Weil and Brady (2016). Nitrogen and phosphorus, $\mathrm{pH}$ and base saturation adapted from Vitousek and Chadwick (2013)
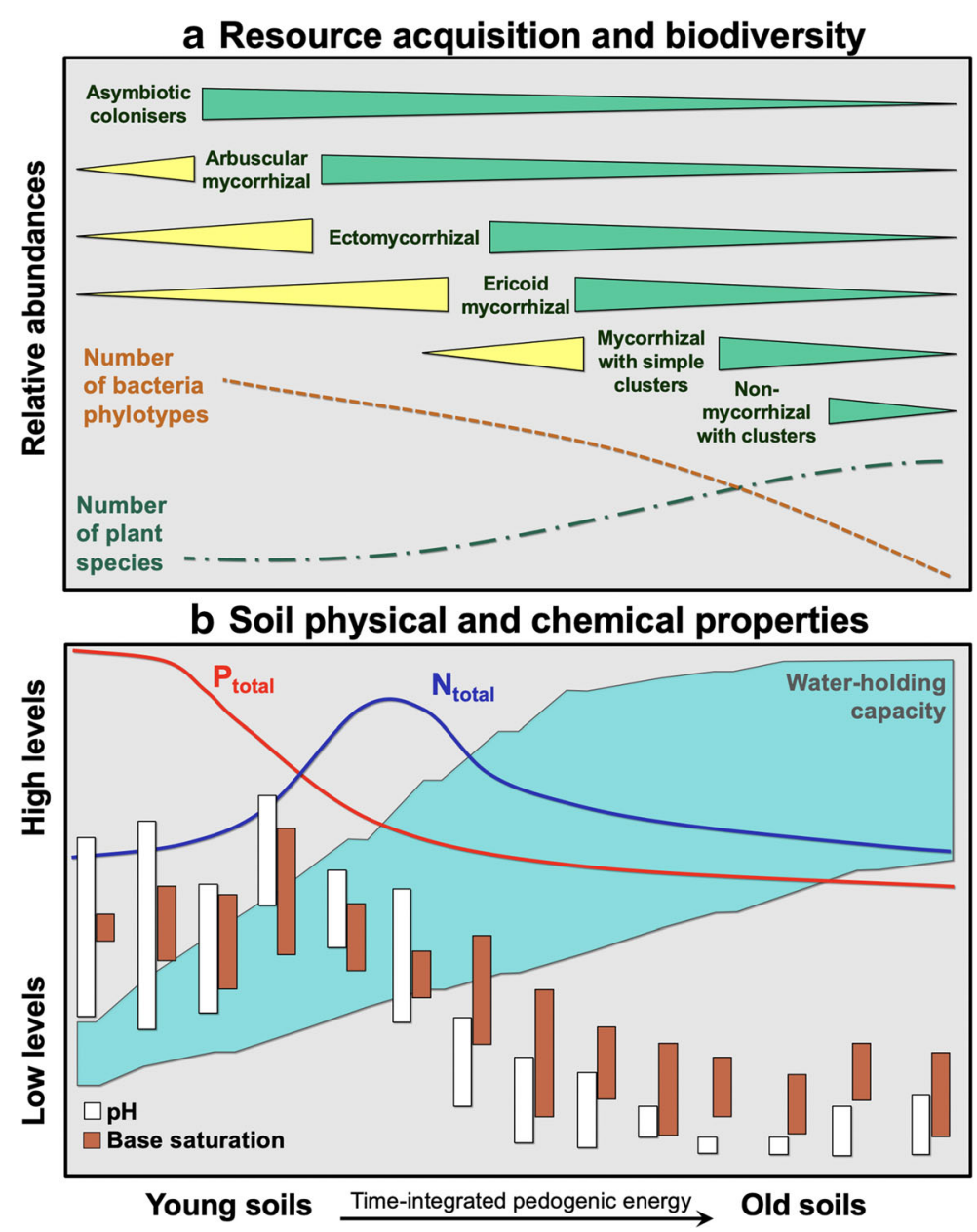

(Or and Wraith 2002), such that preferential mass flow occurs in favor of fast-growing high-transpiring trees (Teste et al. 2010). Nonmycorrhizal (NM) plants predominantly occur in very old landscapes which harbor the poorest most-weathered soils, yet the most biodiverse ecosystems, on Earth (Silva \& Lambers 2018). The strong carboxylate-releasing function of NM roots allows plants to access otherwise unavailable nutrients, such as sorbed $\mathrm{P}$ and other mineral elements. Mycorrhizal networks tend be more localized and weakly developed in NMdominated systems, but this resource use strategy can facilitate resource acquisition by neighboring $\mathrm{AM}$ or EM species through means other than direct connectivity (e.g. via rhizodeposition; Lambers et al. 2018). In summary, root-microbe interactions that influence how water and nutrients move through the SPA interface can be parameterized for certain functional types and their typical pedogenic environments that determine the cost for the construction and maintenance of different $\mathrm{AG}$ and $\mathrm{BG}$ structures.

\section{Interpretive hypotheses: Linking structure and function across scales}

In an effort to synthesize recent developments that point to a new way of thinking - one that reconciles compartmentalized fields of biophysical, biogeochemical, and ecological research as a path towards predictive scaling we propose 10 interpretive hypotheses that can be understood as a primary set of hierarchical relationships across multiple spatial and temporal scales. The proposed hypotheses are exemplified by data from three 
a Initial conditions

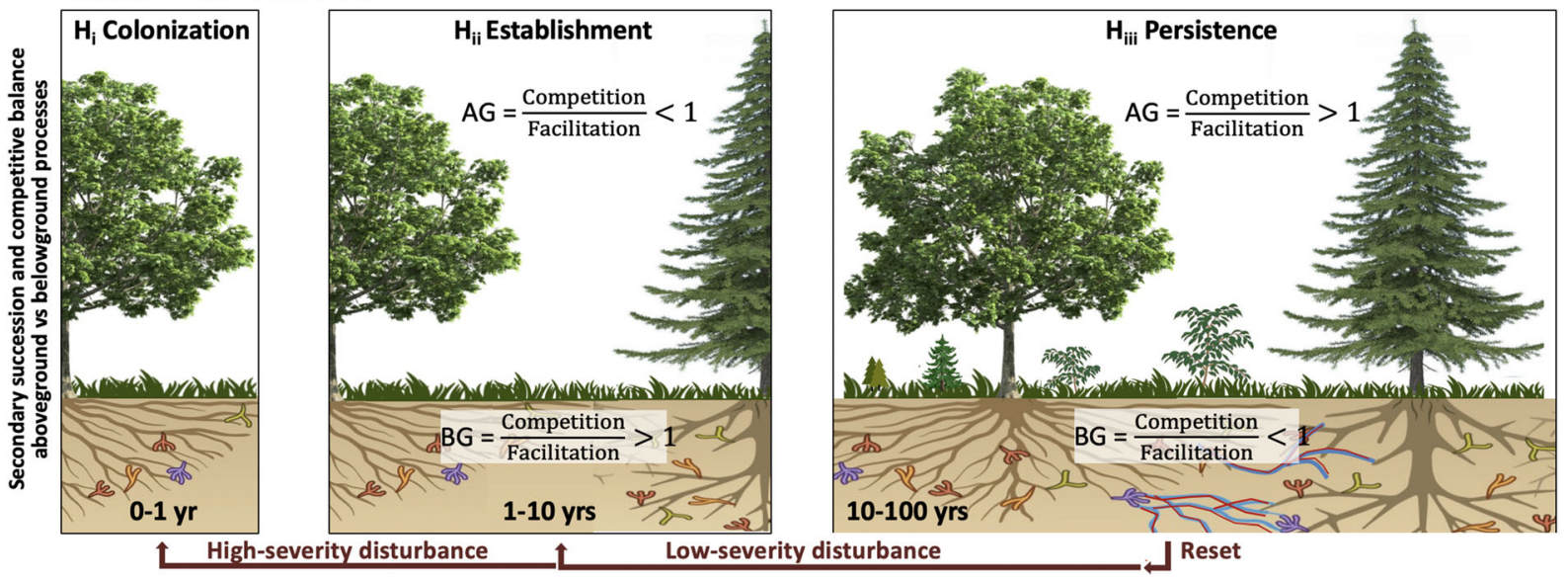

b Drivers of connectivity and resource flow
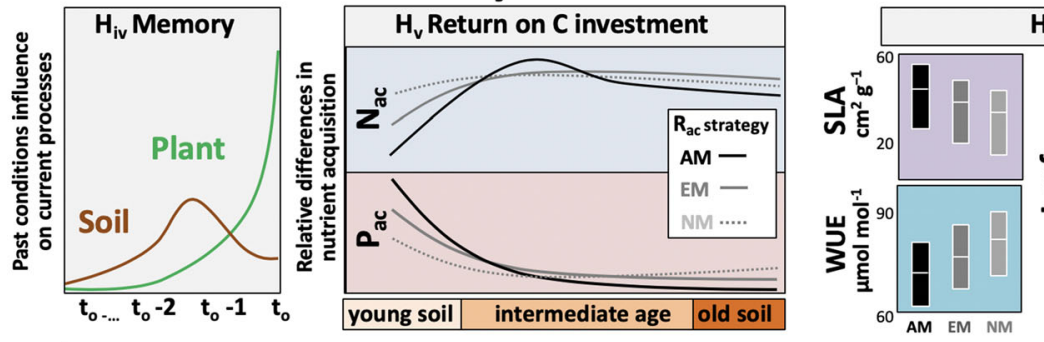

$\mathrm{H}_{\mathrm{vi}}$ Trait-dependent tradeoffs

\section{c Emerging properties}

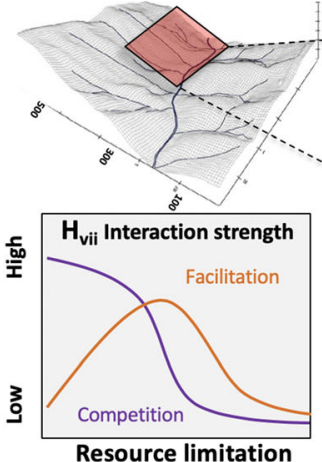

Resource limitation
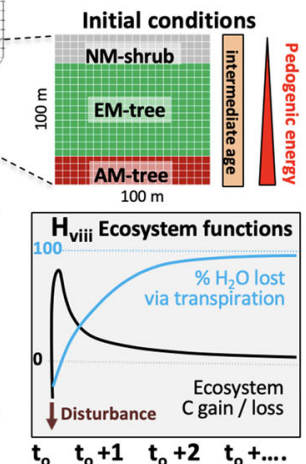

Fig. 3 Interpretive hypotheses and scaling functions. (a) Stochastic processes and initial conditions (Hazard and Johnson 2018). (b) Drivers of connectivity and resource flow described as "memory functions" (Ogle et al. 2015), "return on carbon investment" (Raven et al. 2018), and leaf nitrogen (N) and phosphorus (P) concentrations, which correlate with specific leaf area (SLA) and water-use efficiency (WUE) in AM, EM, and NM plants (Powell et al. 2017). (c) Ecosystem properties emerging from differences

\section{d Response to environmental pressure}

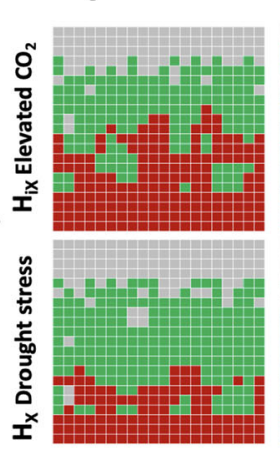

0-1 yr

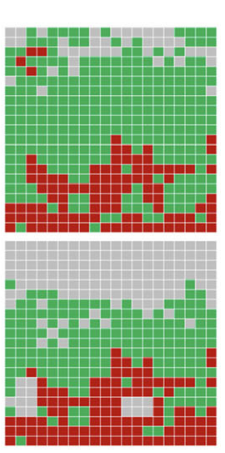

$1-10 \mathrm{yrs}$

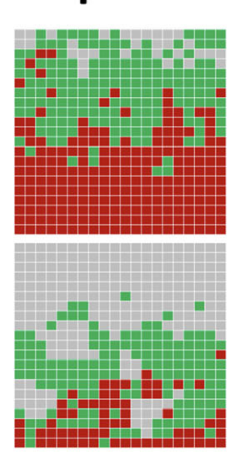

$10-100$ yrs

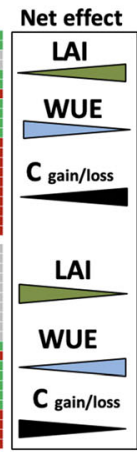

in BG connectivity strength in root-microbe networks (Simard et al. 2015) and their resulting biophysical and biogeochemical baselines expected for carbon (black) and water (blue) balances in a tree-dominated ecosystem (Baldocchi et al. 2018). (d) Landscape-level ecosystem transitions expected in response to elevated atmospheric $\mathrm{CO}_{2}$ concentrations and warming-induced drought stress across a hypothetical topographic gradient of varying pedogenic conditions (Fig. 2) major functional groups (evergreen conifers, broadleaf deciduous, and understory shrubs) and their archetypical AM, EM and NM strategies shown in Fig. 3.
Figure 3a. Initial conditions To represent conditions that shape an ecosystem's development at its inception, we expand on the conceptual model proposed 
by Hazard and Johnson (2018) to relate plant and microbial community composition with environmental filters at the onset of ontogeny. Specifically, three hypotheses are devised to represent common initial conditions:

$H_{i}$ colonization The initial conditions that shape an ecosystem's SPA structure and function include stochastic processes of colonization, such as the ratio of pathogen-to-symbiont dispersal during primary succession or following major disturbances, as well as deterministic processes and environmental filters, such as soil physical and chemical properties, which favor the establishment and persistence of certain types of plant-microbe associations over others.

$H_{i i}$ establishment At the establishment phase, positive AG interactions outweigh negative interactions because facilitation through seeding and microclimate amelioration is more important than competition for light or space (i.e. AG competition / facilitation <1), whereas BG competition for resources between plants and microbes is stronger than symbiotic relationships (i.e. $\mathrm{BG}$ competition / facilitation >1) at that same phase.

$H_{\text {iii }}$ persistence Positive plant-microbe interactions in complementary or interconnected rhizospheres arise as a function of time since the establishment of interdependent plant and microbial communities. There is increasing competition for space and light as the ecosystem develops (i.e. AG competition/facilitation >1) until disturbance events reset the system back to the establishment phase (e.g., after a low-severity canopy opening) or to the colonization stage (e.g., after a severe stand-replacing fire event). The type of disturbance and time since establishment also determine whether or not BG connectivity persists in rootmicrobe networks (i.e. BG competition / facilitation $<1$ ) or is reset to a condition of greater competition, which is characteristic of the colonization phase.

Figure 3b. Drivers of connectivity and resource flow at transient to steady-state conditions Given that transience is a fundamental ecosystem property (Hastings et al. 2018), and considering that plants and soils hold distinct "environmental memory lengths" (Ogle et al. 2015), transitions from dynamic to steady-state conditions arise from SPA interactions as follows:
$H_{i v}$ memory At least two types of memory functions coexist: a long-term memory lag function (brown curve) for soil properties whereby past conditions are more important than current conditions (e.g., past energy inputs at time $\mathrm{t}_{-\mathrm{x}}$ predict current soil nutrient pools and water-holding capacity better than current conditions at time $\mathrm{t}_{0}$; Fig. 2); and a short-term memory lag function (green curve) for an exponential decay exemplified by a plant physiological performance response curve (e.g., climate 3 years ago at $\mathrm{t}_{0-3}$ has a smaller effect on current tree growth and water use than last year's growing season $t_{0-1}$, which has a smaller effect than the current season $t_{0}$ ). Examples of mathematical formulations related to this hypothesis include environmental conditions beyond which $L=t_{x}$ units into the past do not affect current SPA interactions. Other memory functions that have yet to be considered in analyses of environmental memory include biochemical signals transmitted between plant species through microbial symbionts, which can form a type of "immunological memory" (Gilbert and Johnson 2017) that shapes how ecosystems respond to herbivore or pathogen pressure through multiple generations (Ferlian et al. 2018). Once parameterized these and other memory functions could be added to connectivity and resource flow hypotheses to better predict transitions from transient to steady-state conditions.

$H_{v}$ return on investment Pedogenic gradients favor different nutrient acquisition strategies such that threshold for coexistence of two or more strategies can be inferred from their net return on carbon investment (Lambers et al. 2018). Additionally, the demand for limiting resources varies depending on functional group and their typical resource-acquisition strategies (e.g., AM trees, EM trees, and NM shrubs) as indicated by varying fitness levels at different stages of soil development and range of resources available. As variation in soil resources can occur vertically in developing profiles or horizontally in developing landscapes, multiple uptake strategies are possible at any given site, until an abrupt threshold from one uptake mode to another occurs (Fig. 2). In other words, the acquisition modes that are least expensive when the soil nutrient concentration is high, become increasingly more expensive as soil nutrient concentration declines, giving rise to cost-curves that cross over at different stages of soil development, depending on tradeoffs that can be 
parameterized using the carbon cost curve for $\mathrm{N}$, as proposed by Terrer et al. $(2016,2018)$ (red box; Fig. $3 \mathrm{~b}$ ) and the carbon cost curve for $\mathrm{P}$, as proposed by Raven et al. (2018) (blue box; Fig. 3b). As a result, markedly different returns on carbon invested are expected for AM, EM, and NM behaviors depending on how economically roots explore the soil volume for soluble nutrients or invest in exudates to access sorbed nutrient pools.

$H_{v i}$ trait-dependent tradeoffs Dimensionally-independent tradeoffs can be used to predict mass and energy flows from resource demand and growth forms typical of AM, EM, and carboxylate-releasing NM species. For example, the evolutionarily-determined leaf economic spectrum and the GPP-ET (i.e. evapotranspiration) codependence, explained above, represent scale-free tradeoffs that can be parameterized to predict nutrientand water-use efficiency (WUE) from a functional group's leaf morphology or from an ecosystem's canopy structure. The same traits that determine the coupling of leaf and canopy carbon-water functions and carbonnutrient stoichiometry also determine litter production and decomposability (Pietsch et al. 2014). For example, differences in SLA among AM, EM, and NM species are correlated with average nutrient content in mature as well as senesced leaves, and are proportional to differences in productivity and lifespan under different ranges of resource availability (Powell et al. 2017). Variation in transpiration and mass flow at the individual leaf level is also correlated with SLA because stomatal pore area (calculated using stomatal density and size) decreases with increasing SLA within and among plant species (Bucher et al. 2016). At the ecosystem level, LAI serves as a proxy for GPP and ET and can be used to estimate the magnitude and velocity in which water and soluble nutrients move from the soil matrix to the rhizosphere. As discussed above, water and nutrients in solution can be redistributed through root-microbe networks as a result of water potential gradients among different species. Similarly, stoichiometric gradients also influence the redistribution of insoluble nutrients through root-microbe growth and mining, leading to asymmetric patterns of resource flow and accumulation from which contrasting ecosystem properties emerge.

Figure 3c. Emerging ecosystem properties and functions Here, we illustrate hypothetical outcomes of spatially explicit simulations that combine metrics of ecophysiological performance and resource flows to describe how local SPA interactions reverberate across landscapes.

$H_{v i i}$ interaction strength The strength of plant-microbe interactions that control carbon, water, and nutrient flows varies in response to resource availability, creating divergent structural patterns across landscapes. For example, extra-radical mycelial growth such as AM fungi and short-lived EM fungi, connect plant roots within close proximity or for a short duration, but those are often nested within more extensive multi-genomic networks through which rhizomorphs of specialized hyphal strands span several tens of meters in length, enabling the transport of water and nutrients (Simard et al. 2012). Facilitative mutualistic plant-microbe interactions are expected to equalize resource distribution - a stabilizing force - under increasing resource limitation; conversely, competition is expected to increase in more productive nutrient-rich environments, leading to asymmetric resource flows. Asymmetric transport and retention are expected to mirror the spatial distribution of species with varying transpiration rates and biomass stoichiometry (Creed et al. 2014; Saha and Setegn 2015). As soil organisms encounter or colonize roots, their associated carbon demands are partitioned such that when symbiotic or asymbiotic nutrient inputs from microbial communities (e.g., from free-living diazotrophs) are superimposed over heterogeneous soil resources, a mosaic of ecosystem forms and functions can co-exist. When resource limitation is too severe, as in very old landscapes, the overall diversity of species and resource acquisition strategies tend to increase and NM functional types tend to become prominent (Lambers et al. 2018). Thus, spatialized simulations of resourcetransfer rates typical of different ecosystem states, soil development gradients, and level of stochastic or chronic environmental stress can be developed using existing models (e.g., cellular automata propagations) for which transient to steady states arise from species-specific parameters (e.g., WUE and nutrient use) constrained by a finite pool of soil resources (Saha et al. 2010; Miralles-Wilhelm 2016; Zhai et al. 2016).

$H_{\text {viii }}$ carbon-water baselines The manifestation of local strength interactions at the ecosystem scale can be predicted from a select set of environmental and biological factors (e.g., atmospheric composition, precipitation, temperature, resource availability, AG structure and 
BG network interaction strength), which directly and indirectly affect baseline carbon, water, and nutrient cycling. For example, in the absence of major disturbances, SPA interactions tend to move ecosystems increasingly closer to a state where long-term accumulation of carbon occurs (black curve; Fig. 3c) and in which water moves primarily through transpiration (blue curve; Fig. 3c) (Evaristo et al. 2015; Medlyn et al. 2015). Under chronic environmental stressors (e.g., persistent warming-induced drought or rising atmospheric $\mathrm{CO}_{2}$ concentration), the relative abundances of dominant functional types and their role in maintaining rootmicrobe connectivity can change, causing marked shifts in ecosystem functions. The magnitude and direction of such shifts depend on soil properties. For example, in a synthesis of 544 site-years of eddy-covariance ecosystem-level carbon and water flux data (Baldocchi et al. 2018) shows how warming-induced drought caused a decline in GPP and ET, especially in areas where soil nutrients are limiting, despite an expected increase in photosynthetic rates caused by rising atmospheric $\mathrm{CO}_{2}$ concentrations. The same data synthesis shows that too much rain can reduce carbon uptake by limiting sunlight in humid regions, and that microbial respiration, which increases exponentially with temperature, can bring ancient forest ecosystems to "the verge of switching from being carbon sinks to carbon sources" (Baldocchi et al. 2018). Thus, coupled carbon-water-nutrient excursions (relative to historic baselines) can be used to anticipate the net outcome of SPA-mediated responses to environmental pressure.

Figure 3d. Response to chronic environmental pressure The two most pervasive, and thus mostcommonly studied climatic stressors affecting terrestrial ecosystems, are warming-induced stress and elevated $\mathrm{CO}_{2}$ levels. These chronic pressures have very different effects on the physiological performance of individual plants as well as on the function of entire ecosystems depending on soil resources (Reich et al. 2014), and on how the terms of trade with dominant types of rootmicrobe symbioses (Terrer et al. 2018). Generally, soil resource limitation favors the dominance of conservative resource-efficient growth strategies at the expense of productivity such that plant communities on infertile soils are less sensitive to climate warming or elevated $\mathrm{CO}_{2}$ (Franco et al. 2014; Harrison et al. 2015). Experimental research with a wide range of species has consistently shown that $\mathrm{CO}_{2}$ stimulation increases plant water- and nutrient-use efficiency, often leading to reduced mass flow and alteration in the stoichiometric coupling of all major nutrients (Myers et al. 2014; Tian et al. 2018). It follows that changes in mass flow and stoichiometry should impact the biotic interaction strength and return on carbon investment in plantmicrobe networks in a predictable manner. For example, assuming that climatic and edaphic conditions do not prohibit the establishment of AM, EM, and NM species across a typical montane landscape in which water-holding capacity and $\mathrm{N}$ availability are expected to decrease from more productive foot-slope environments toward less productive hill-slope soils (where $\mathrm{P}$ and other mineral nutrients availability is relatively high), we can predict the most likely outcome of environmental change on SPA interactions. Specifically, taking ecosystem LAI and as an integrated proxy for ecosystem productivity, from which GPP and ET can be inferred, the following scenarios are to be expected in response to persistent warming and elevated $\mathrm{CO}_{2}$ :

$\mathrm{H}_{i x}$ response to elevated $\mathrm{CO}_{2}$ concentrations Elevated atmospheric $\mathrm{CO}_{2}$ concentrations increase canopy cover and the amount of $\mathrm{CO}_{2}$ fixed per unit of water transpired, but it can also result in decreased nutrient flow from the soil matrix to individual plants. Landscape patterns in this scenario include changes in return on investment curves (Raven et al. 2018), which cross over along the axis of nutrient concentration at intermediate soil age. In this example, foot-slope soils are assumed to be consistently exposed to greater pedogenic energy $(\mathrm{PE})$, and thus bedrock weathering $(\omega)$, than hill-slope soils due to historical differences in water inputs, temperature and GPP. Thus, differences in soluble and insoluble nitrogen or phosphorus concentrations favor different acquisition strategies over scales of seasons to centuries. For the sake of simplicity, we only represent the most likely functional type to dominate a plot $(10 \times 10 \mathrm{~m})$ and the collection of such plots that switches from one state to another as a result of interactions between soil resource acquisition strategies. In this example, varying nutrient concentrations should be thought of as occupying a frequency distribution, rather than a single value along vertical profiles, such that coexistence should be possible, until an abrupt threshold of uptake mode is reached. 
$H_{x}$ response to warming-induced stress The benefits of $\mathrm{CO}_{2}$-induced increases in WUE can be outweighed by the negative effect of warming-induced drought stress (Gómez-Guerrero et al. 2013). The outcome of this effect is the persistence and increasing dominance of NM species, especially in poorly-developed soils, under low canopy cover, high WUE and low carbon sequestration (Harrison et al. 2015; Davis and Gedalof 2018). However, under moderate baseline stress (e.g. in deeper soils with greater WHC) warming leads to other types of response. For example, in mixed temperate forests, the intrinsic WUE of nine dominant tree species across topographic gradients, normalized for differences in vapor pressure deficit (VPD) across sites, varies predictably with SLA > LAI > PM (i.e. parent material) (Maxwell et al. 2018a). Those same authors found that shifts in species composition from EM conifers to AM deciduous trees, presumably driven by climate warming since the 1950 s, newnbsp; caused a major increase in water loss through transpiration per unit of $\mathrm{CO}_{2}$ assimilated (i.e. a decline in WUE ranging from 10 to $60 \%$, depending on PM). This process can in the long run decrease water availability and increase the likelihood of an ecosystem regime shift toward a less productive drought-adapted species dominance in certain portions of the landscape depending on soil properties.

\section{Numerical integration}

The hypotheses listed above can be tested by the integrated analysis of dynamic locally-controlled processes (e.g., leaf gas exchange and root-microbe associations) and slow-moving processes (e.g., pedogenesis). To this end, we propose a simple mathematical formulation that links species demands and a finite pool of resources. In this formulation, water inputs from precipitation can accumulate in the soil where aqueous fluids are assumed to be incompressible; thus, any increase in connectivity between plants and microorganisms or between different plants through root-microbe networks requires a proportional increase in the amount of water and solutes stored in the biological compartment between the sites of uptake and growth. This means that the velocity of flows in individual plants serves as a local signal of large-scale processes affecting the broader network (Heaton et al. 2010), as determined by AG and BG interactions that effectively reflect the overall "plumbing of the [SPA] critical zone" (Brantley et al. 2017). Resource-sink gradients are modeled in agreement with expected transpirational mass flow using empirical examples that show preferential movement of resources from slow- to fastgrowing plants which can be reversed depending on the connectivity strength of new organisms added to the network (Simard et al. 2015).

The influence of SPA interactions on plant WUE can be used to assess biologically-controlled variation in mass flow across scales. The term WUE has been traditionally defined as the ratio of net amount of carbon assimilated via photosynthesis (A) to the mass of water lost from the leaves to the atmosphere via transpiration (T). Several methods can be used to measure WUE including leaf gas exchange, stable isotope fractionation, and eddy covariance. However, measurements of WUE are not always consistent among those different approaches. For example, significant discrepancies include differences between discrete leaf gas exchange measurements for different co-existing plant functional groups which are not apparent in ecosystem-scale eddy covariance data (Medlyn et al. 2017). Despite this limitation, significant shifts in biophysical processes that govern WUE can be inferred from molecules to whole plants and ecosystems using time-integrated measurements of stable carbon isotopes. The inference of WUE from plant cellulose isotope ratios $\left(\delta^{13} \mathrm{C}\right)$ was first proposed by Farquhar et al. (1982), who showed that $\delta^{13} \mathrm{C}$ ratios reliably record variation in $\mathrm{A} / \mathrm{T}$ because both WUE and $\delta^{13} \mathrm{C}$ are controlled by intercellular levels of $\mathrm{CO}_{2}\left(\mathrm{C}_{\mathrm{i}}\right)$, which vary predictably with leaf-to-air vapor pressure deficit (VPD). If VPD can be assumed constant among co-existing plants at a given site, then $\delta^{13} \mathrm{C}$ values will be linearly correlated with canopy $\mathrm{A} / \mathrm{T}$ of each plant (Marshall et al. 2007). However, VPD often varies across plant functional types whose leaves differ in morphology. As a result, physiological ecologists often calculate what is known as the intrinsic water-use efficiency (iWUE) of a plant from $\delta{ }^{13} \mathrm{C}$ data. The iWUE, or the ratio of $\mathrm{A}$ to stomatal conductance $\left(\mathrm{g}_{\mathrm{s}}\right)$ is correlated with transpiration for most dominant trees and understory species, but is not dependent on assumed VPD (Farquhar and Richards 1984). The iWUE of a plant can be calculated from the isotopic fractionation between known atmospheric $\mathrm{CO}_{2}$ and measurable plant bulk biomass or specific compound, such as cellulose as follows:

$\Delta^{13} \mathrm{C}=\left(\delta^{13} \mathrm{C}_{\text {air }}-\delta^{13} \mathrm{C}_{\text {plant }}\right) /\left(1+\delta^{13} \mathrm{C}_{\text {air }} / 1000\right)$

where $\Delta^{13} \mathrm{C}$ is fractionation of ${ }^{13} \mathrm{C}, \delta{ }^{13} \mathrm{C}_{\text {air }}$ is the carbon isotope ratio of $\mathrm{CO}_{2}$ and $\delta^{13} \mathrm{C}_{\text {plant }}$ is the carbon isotope ratio of cellulose. 
$\mathrm{C}_{\mathrm{i}}=\mathrm{C}_{\mathrm{a}} *\left(\Delta^{13} \mathrm{C}-a\right) /(b-a)$

$\mathrm{iWUE}=\mathrm{A} / \mathrm{g}_{\mathrm{s}}=\mathrm{C}_{\mathrm{a}} *\left[1-\left(\mathrm{C}_{\mathrm{i}} / \mathrm{C}_{\mathrm{a}}\right)\right] * 0.625$

where a is the fractionation against ${ }^{13} \mathrm{CO}_{2}$ during diffusion through the stomata in the gaseous phase and $\mathrm{b}$ is the net fractionation due to carboxylation and 0.625 is the ratio of diffusivity.

In cases where photosynthesized molecules, plant functional traits, and environmental data can be analyzed in conjunction, $\delta^{13} \mathrm{C}$ data can be used as a scaling tool for WUE. For example, species-specific iWUE deriving from leaf $\delta^{13} \mathrm{C}$ ratios can be normalized by leaf morphology (e.g., specific leaf area - SLA) and/or divided by downscaled VPD to the level of a stand for which pedogenic development is known. Both VPD and pedogenic development affect soil water-holding capacity (WHC) across landscapes. For this reason, recent studies have considered a normalized index for actual WUE, termed "standardized water use", where actual $\mathrm{WUE}=\mathrm{A} / \mathrm{T}=\mathrm{iWUE} / \mathrm{VPD}$ downscaled and stratified across landscapes by local to stand-level WHC and averaged community-weighed SLA (Maxwell et al. 2018a). This type of standardization can be understood as a "conservative approach that minimizes interspecific differences relative to intensified gradients that occur due to variation in soil properties and leaf morphology". Finally, in cases where net primary productivity can be quantified for the same time period for which WUE is calculated - e.g., annual tree-ring basal area increments coupled with $\Delta^{13} \mathrm{C}$ time series (GiguèreCroteau et al. 2019; Liles et al. 2019), SPA interactions can be simplified and scaled to estimate transpirational mass flow.

At the ecosystem level, the contribution of all plant species to soil organic matter $\delta^{13} \mathrm{C}$ serves as an integrated proxy for LAI, and thus as a metric of canopy density used for predicting primary productivity and ET across biomes (Ladd et al. 2014). Therefore, the chemical composition of soil organic matter provides a time-integrated, productivity-weighted measure of stand-level processes, reflecting the isotopic signatures of plant biomass deposited seasonally as well as the amounts and isotopic signatures of plant-derived carbon that accumulates in the soil at decadal to centennial time scales. To complement $\delta^{13} \mathrm{C}$ data independent measurements oxygen stable isotope ratios $\left(\delta^{18} \mathrm{O}\right)$ can be performed using plant water or tree ring cellulose (Oliveira et al. 2005; Johnstone et al. 2013; Earles et al. 2016) or cellulose-derived sugars extracted from soil samples (Zech and Glaser 2009; Zech et al. 2012; Tuthorn et al. 2014; Zech et al. 2014). This approach allows for scaling oxygen isotope measurements from molecules to ecosystems in contemporary settings, as the retention time of sugars in soils is on the order of 10-20 years (Schmidt et al. 2011). For long-term reconstructions, tree ring records are useful to differentiate the effects of rising $\mathrm{CO}_{2}$ stimulation of $\mathrm{A}$ from drought-stressinduced $\mathrm{g}_{\mathrm{s}}$ downregulation (Dietrich et al. 2016; Giguère-Croteau et al. 2019). In some cases, tree ring isotope data can be combined with remote sensing to scale responses from individual trees to landscapes and to quantify climate-induced shifts in forest productivity and WUE (Correa-Díaz et al. 2019). For longer time integration of whole ecosystem water balance, long-chain aliphatic fatty alkanes, alkanols and alkanoic acids deposited from plant cuticular waxes can be used. These compounds persist in soils and sediments with isotopic signals that are stable over geologic timescales (Lützow et al. 2006; Sachse et al. 2012). Typically, the study of plant-derived lipids for water balance reconstructions targets hydrogen isotope ratios $(\delta \mathrm{D})$ of specific molecules, but recent studies have proposed the joint characterization of $\delta \mathrm{D}$ and $\delta^{18} \mathrm{O}$ values of lipid compounds as a means to infer changes in water balance (total input minus ET loss), when source water values can be estimated (Maxwell et al. 2014; Silva et al. 2015c; Maxwell et al. 2018b).

The biogeochemical consequences or biophysical SPA interactions can be approximated from autocatalytic connectivity functions that link molecules to landscapes as a "nested hierarchical" system (Farnsworth et al. 2017). For example, "terms of biological trade" (i.e. fundamental biological tradeoffs) that govern carbon assimilation and WUE can be estimated from first physical principles. This is possible because physical laws are manifested in water potential and nutrient stoichiometry gradients that define "return on carbon investment" ( () , as a marginal increase in resource acquisition $\left(R_{a c}\right)$, relative to the total amount of carbon invested belowground $\left(C_{b g}\right)$. In other words, the magnitude and direction of carbon, nutrient, and water exchange can be quantified from individual organisms as vectors that create time-integrated spatial patterns across landscapes. For example, the hypotheses above focus on average relationships involving three major functional groups (i.e., EM evergreen conifers, AM broadleaf 
deciduous, and NM understory shrubs) assuming that BG connectivity shapes the magnitude and direction of carbon and water exchange from trees as vectors that create landscapes patterns as follows:

$\frac{R_{a c}}{C_{b g}}=\mho^{-1}$

$C_{b g}=C_{\text {root }}+C_{\text {trans }}$

$B=G P P-C_{b g}-C_{\text {resp }}$

where $\mho^{-1}$ is the inverse of return on investment based on a sink strength function of $R_{a c}$, which can be directly measured in terms of carbon-to-nutrient ratios to describe the degree to which growth is limited by a given resource; $\mathrm{C}_{\text {root }}$ is the amount of carbon invested in root production; $\mathrm{C}_{\text {trans }}$ is the amount of carbon transferred to soil fungi; this term is absent for NM carboxylatereleasing species (Raven et al. 2018), and for AM and EM species it is inversely proportional to the measured pool of carbon available for biomass productivity (B) as a fraction of gross primary productivity (GPP) minus $C_{b g}$ and autotrophic plus heterotrophic respiration $\left(C_{\text {resp }}\right)$.

The simplest formulation (linear) of resource-sink strength described above becomes increasingly complex (non-linear) as soils age and its effect on the probability of certain $R_{a c}$ strategies to outcompete others are taken into consideration. As species composition change across pedogenic gradients, ecosystem-scale $\mho$ is the inverse of the sum of $R_{a c}$ of coexisting species which can be aggregated as AM, EM, or NM functional types and their BG connectivity (or lack thereof), as follows:

$\mho^{-1}=\Sigma R_{s p}+\left(1-R_{s p}\right) \cdot e^{\frac{-\omega}{s p}}$

$\omega=P M \cdot P E$

where $R_{s p}$ is the minimal level of resource needed to ensure survival of a given species or functional type; $\omega$ is the soil-specific coefficient that integrates physical development metrics related to bedrock weathering, which include water-holding capacity and the expected range of acquirable (soluble or insoluble) nutrient pools - approximated on the basis of known weatherability indices for different parent materials (PM) and pedogenic energy (PE) calculated from precipitation and temperature and GPP as proposed by Rasmussen and Tabor (2007); and $r_{s p}$ is the rate at which the overall resource pool is depleted as a dynamic fraction of species- or functional-group-specific B.

Different functional groups have different $\mho^{-1}$ for water and nutrients, which cause asymetric depletion of soil resources at the plot level, indirectly lowering the landscape-level pool of resources through resource transport or accumulation. Changes in ecosystem structure and function can thus be simulated from soil and species- or functional-group-specific parameters corresponding to different demands for resources to maintain GPP, transpiration, and biomass turnover:

$\eta \frac{\partial s}{\partial t}+\frac{\partial B_{i}}{\partial x_{i}}=-\chi$

$\eta \frac{\partial(s C)}{\partial t}=-\frac{\partial\left(B_{i} C\right)}{\partial x_{i}}+\frac{\partial}{\partial x_{i}}\left[\eta s D_{i j} \frac{\partial C}{\partial x_{j}}\right]-\theta$

$B_{i}=-\left[k_{w}(s) K_{i j}\left(x_{i}\right) q_{i j}\left(x_{i}\right)\left\{\frac{\partial \psi}{\partial x_{j}}+1\right\}\right]$

where $\eta$ is the soil-age-specific porosity coefficient; $\mathrm{s}=\mathrm{s}(\mathrm{xi}, \mathrm{t})$ is the soil saturation through time (t) across the spatial coordinate system $\mathrm{x}_{\mathrm{i}}(\mathrm{i}=1,2,3) ; \mathrm{B}_{\mathrm{i}}=\mathrm{B}_{\mathrm{i}}\left(\mathrm{x}_{\mathrm{i}}, \mathrm{t}\right)$ is the biologically-controlled flow rate vector determined by $\mho^{-1} *$ WUE - or the ratio between $\mathrm{CO}_{2}$ assimilated per unit of water lost through transpiration; $\chi=\chi\left(\mathrm{s}, \mathrm{x}_{\mathrm{i}}, \mathrm{t}\right)$ is the rate of water loss including evaporation and transpiration, a function of $\eta$, climate, atmospheric VPD, soil depth, and $\mathrm{B} ; \mathrm{C}=\mathrm{C}\left(\mathrm{x}_{\mathrm{i}}, \mathrm{t}\right)$ is the soil-age-specific concentration of nutrients; $\mathrm{D}_{\mathrm{ij}}$ is the solute dispersion coefficient; $\theta=\theta\left(\mathrm{s}, \mathrm{C}, \mathrm{M}, \mathrm{x}_{\mathrm{i}}, \mathrm{t}\right)$ is the rate of resource uptake; $\mathrm{k}_{\mathrm{w}}(\mathrm{s})$ is the relative permeability of the soil $(0<\mathrm{kW}<1), \mathrm{K}_{\mathrm{ij}}$ is the hydraulic conductivity; $\mathrm{q}_{\mathrm{ij}}$ is the $\mathrm{BG}$ connectivity of different individuals in mycorrhizal networks; and $\psi=\psi\left(\mathrm{s}, \mathrm{x}_{\mathrm{i}}, \mathrm{t}\right)$ is the water potential gradient between root-fungal surfaces and the soil matrix - a function of species SLA and $q$ described by $\mathrm{C}_{\text {trans }}$ coefficients for different $\mathrm{R}_{\mathrm{ac}}$ strategies.

Equations (7-11) represent the coupling of hydrologic transport and vegetation cover. This implementation can be understood as general model for spatiotemporal 
scaling capable of identifying ecosystem properties emerging from molecular and organismal processes. This is attained at the scale of seasons through decades (scales 3-6; Fig. 1), as well as from decades to centuries (scales 6-9; Fig. 1), through Michaelis-Menten kinetics for resource sink $\phi$ (Kapoor et al. 1997):

$\phi=\frac{r M C}{b+C}$

$\frac{\partial M}{\partial t}=\frac{f C M}{b+C}-\lambda M$

$$
\frac{\partial d}{\partial t}=\lambda M-\varepsilon d
$$

where, $\mathrm{M}=\mathrm{M}(\mathrm{xi}, \mathrm{t})\left[\mathrm{ML}^{-2}\right]$ and $\mathrm{d}=\mathrm{d}(\mathrm{xi}, \mathrm{t})\left[\mathrm{ML}^{-2}\right]$ are the insoluble nutrient pools in tissues and decaying biomass, respectively; $\mathrm{b}$ is the species- of functionalgroup-specific parameterized half-saturation nutrient concentration $\left[\mathrm{ML}^{-3}\right]$ for biomass growth; $\mathrm{f}\left[\mathrm{T}^{-1}\right]$ is the deposited biomass rate (fraction of $\mathrm{B}$ deposited per mass of nutrient uptake over time), $\lambda\left[\mathrm{T}^{-1}\right]$ is the estimated rate of biomass input to the $\mathrm{C}_{\mathrm{bg}}$ and $\varepsilon\left[\mathrm{T}^{-1}\right]$ is the decomposition rate of deposited organics.

Equations 12-14 describe the variation in productivity and decomposition with associated stoichiometric sinks that influence resource flows, assuming that carbon to nutrient ratios correlate with biomass accumulation and decay, in a reversible patterning for finite carbon and water (Lago et al. 2010).

Significance for climate change mitigation

Accelerating the removal of carbon from the atmosphere to mitigate climate change under increasingly limiting land and water resources is the defining challenge of our time. Landowners and policymakers are seeking new ways to boost ecosystem productivity and carbon sequestration while optimizing the use of soil water and nutrients. Physical laws govern a fundamental tradeoff between carbon sequestration and water conservation, in which the photosynthetic removal of $\mathrm{CO}_{2}$ from the atmosphere depends on the amount of water moving from the soil to the air through transpiration (Baldocchi and Peñuelas 2019). The structural limits of this functional tradeoff are well known for several plant species, but ecological interactions at the SPA interface make it difficult to predict those limits at scales relevant for policy or management. Much progress has been made to quantify and scale SPA-mediated climate forcings through eddy-covariance sensors (Baldocchi et al. 2014, 2018) and remote-sensing (Asner et al., 2016a, b). Large datasets can now be used to generate processbased predictions of changes in ecosystem structure and composition including many species that represent functional groups other than those used for the hypotheses described in Fig. 3. Changes in species composition do not always correspond with changes in functional traits (Enquist et al. 2015), but their effect on soil properties and microbial processes must be considered to anticipate the costs and benefits of long-term carbon storage at local, regional, and global scales.

To translate basic science into useful policy and management goals we must first characterize how fastchanging SPA properties (e.g., species composition and physiological performance of dominant species) interact with slow-changing landscape features (e.g., topography and soil development) to control carbon-water-nutrient relations. The importance of those interactions can be measured in terms of plantderived carbon accumulation as a central component of soil development through litter deposition, root growth, and rhizodeposition of organic compounds. For example, rhizodeposition of carbon adsorbed onto poorly crystalline minerals is thought to be "the most important mechanism for preservation of soil carbon" (Mikutta et al. 2006). Moreover, the engineered use of rootmicrobial processes to enhance silicate weathering has been suggested as a promising, albeit costly, technique for accelerated $\mathrm{CO}_{2}$ draw down (Schlesinger and Amundson 2018). Accordingly, shifts in vegetation composition, distribution, or productivity must be considered alongside root-microbe associations, which influence the rates at which bedrock weathering progresses, and vertical soil development occurs. Physical and chemical transformations of bedrock, in turn, regulate drought resistance (O'Geen et al. 2018) and the potential for $\mathrm{CO}_{2}$-induced stimulation of plant and microbial growth (Harrison et al. 2016; Silva \& Anand 2013). Increases in primary productivity can abate $\mathrm{CO}_{2}$ emissions, functioning as a negative forcing on temperature, but significant complexities surround the interactive effects of changes in climate and $\mathrm{CO}_{2}$ levels on plant growth and soil development (Fig. 4).

The magnitude of the net ecosystem carbon sink also depends on the large respiratory costs of plant and 


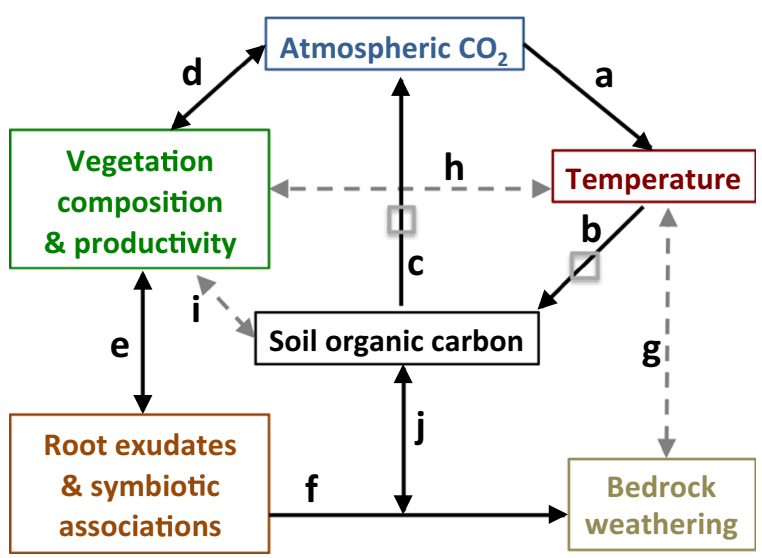

Fig. 4 Conceptual model connecting SPA interactions from ecosystems to the Earth system. Solid arrows represent direct effects (e.g., rising $\mathrm{CO}_{2}$ levels lead to higher temperatures). Grey squares indicate inverse effects (e.g., increasing temperatures lead to decreasing soil carbon stocks). A positive destabilizing feedback loop links atmospheric $\mathrm{CO}_{2}$ concentration, temperature, and soil carbon concentration (a-b-c). A negative stabilizing feedback loop links atmospheric $\mathrm{CO}_{2}$, vegetation productivity, and root-microbe associations (d-e-f), which affect and are affected by soil carbon concentration (j). Dashed arrows represent uncertain feedbacks involving changes in water regime and/or temperature and their interactive effect on plant and soil microbial processes (g-h-i). Adapted from Amundson et al. (2015) and Taylor et al. (2012).

soil microbial communities. Plant and soil respiration increase with temperature, given sufficient soil moisture, but decline if soils are too dry and tend to scale with carbon inputs into the rhizosphere (Baldocchi 2008). In our conceptual scheme (Fig. 4), feedbacks involving plant and microbial respiration are implicitly represented by dashed arrows that illustrate uncertain responses triggered by rising temperatures and/or water regime shifts (e.g., manifested as variation in input from precipitation versus total loss from ET) whose joint impact on plant and microbial metabolic rates and respiration remains difficult to predict. In general, water stress reduces ecosystem photosynthesis more than respiration, however, the impact of water stress on GPP differs based on climate and ecological factors (e.g., light, rainfall, temperature, soil properties, species composition, and phenology) with limiting rainfall causing physiological declines in photosynthesis in temperate regions and too much rain limiting photosynthesis by limiting light in the humid tropics (Baldocchi et al. 2018).

We have known for some time that atmospheric circulation patterns, which influence climate variability, are strongly influenced by carbon-water-nutrient relations controlled at the SPA interface. For example, 1163 site-years of eddy-covariance data from 155 sites across the globe show scale-free positive relationship between GPP and ET, both of which increase with tree cover (Baldocchi and Peñuelas 2019). From a biophysical perspective, there are very small differences between the carbon-water tradeoff as manifested in managed or unmanaged ecosystems. For example, a bottom-up biophysical model that couples surface energy balance and stomatal conductance shows that forests and tree crops use more water than other systems (including savannas, grasslands, and agricultural fields) that coexist in working landscapes (Baldocchi et al. 2019). This finding is explained by long growing seasons and rapid transpiration rates of tree canopies. For example, the amount of carbon that can be drawn down through photosynthesis each year increases with absorbed sunlight as a direct function of LAI. In wet climates or subalpine montane environments forests achieve closed canopies (LAI $\sim 5 \mathrm{~m}^{2} \mathrm{~m}^{-2}$ ) similar to those of and irrigated orchards which are several-fold higher than the typical LAI of dry landscapes occupied by sparse vegetation (LAI 1 to 2 $\mathrm{m}^{2} \mathrm{~m}^{-2}$ ). Thus, efforts to enhance forest productivity to maximize carbon sequestration can negatively impact water yields (Perry and Jones 2017).

Biogeochemical processes complicate the possibility of scaling carbon-water relations from leaves to landscapes. For example, metasedimentary bedrock weathering in montane regions has been shown to contribute significant amounts of $\mathrm{N}$ to plants (Morford et al. 2016), which implies that photosynthetic efficiency (which is $\mathrm{N}$ limited) can covary with lithology. As another example, the discovery of plant isoprene gas emissions from many dominant tree species as a mechanism to attenuate drought stress via aerosol-induced rain formation (Taylor et al. 2018), suggests a more complex relationship between climate and GPP than previously realized. Additionally, biogeographical shifts in response to climatic or atmospheric change can lead to significant alterations of carbon-water-nutrient relations. For example, warming or $\mathrm{CO}_{2}$-induced stimulation of tree growth can promote forest expansion toward high altitudes resulting in increased soil water use and progressive nutrient limitation (e.g., Silva et al. 2016). On the other hand, elevated $\mathrm{CO}_{2}$ also increases WUE of trees and forests an effect that varies strongly with nutrient availability, a function of pedogenic development, with as-of-yet unquantified consequences for ET and precipitation 
variability. By one estimate, $\sim 80 \%$ of the net land water loss to the atmosphere happens through plant transpiration (Jasechko et al. 2013). Although this estimate varies with location and statistical treatment (Coenders-Gerrits et al. 2014), even the most conservative estimate indicates that transpiration exerts dominant control over the terrestrial carbon and water balances (Schlesinger and Jasechko 2014). Therefore, we must better represent SPA interactions that vary with vegetation cover and pedogenic thresholds in managed and unmanaged landscapes as those interactions shape the limits of biogeographical, biophysical, and biogeochemical processes affecting climatic stability.

On the temperature-forcing front, the effect of warming and atmospheric $\mathrm{CO}_{2}$ on primary productivity and terrestrial carbon accumulation depends on water as well as organic and mineral nutrient pools (Terrer et al. 2019). In regions where warming is associated with increasing soil water and nutrient availability, productivity is expected to increase (Salzer et al. 2009, Körner 2012, Shi et al. 2015; Silva et al. 2016). However, productivity has declined in regions where nutrient limitation or ET outpace the photosynthetic benefits of elevated $\mathrm{CO}_{2}$ levels (Mankin et al. 2017). Although there is some evidence of a recent global pattern of land "greening", which could indicate increasing primary production due to warming and elevated $\mathrm{CO}_{2}$ (Zhang et al. 2015), the long-term effect of this trend on carbon storage is uncertain because soil carbon accumulates at very slow rates. Furthermore, microbial respiration can increase significantly and, as a result, soil carbon pools can decompose rapidly in response to changes in land cover and climatic conditions even when those same factors stimulate primary production. For example, the human impact on land since the onset of plant domestication and agricultural production is estimated to have resulted in the loss of 40 to $100 \mathrm{Pg} \mathrm{C}$ (Joosten 2015). The current global soil carbon pool is estimated to be over three times larger than the atmospheric pool (Le Quéré et al. 2018). However, warming temperatures could cause soils to lose another $55 \mathrm{Pg}$ of organic carbon by 2050 , that is $\sim 15 \%$ of the projected anthropogenic $\mathrm{CO}_{2}$ emissions for the same period (Crowther et al. 2016). In addition, emissions of greenhouse gases other than $\mathrm{CO}_{2}$ can be caused by increasing plant cover. For example, enlarged lenticels and aerenchyma that enhance oxygenation of root systems in flooded areas facilitate the movement of methane from the soil to the air (Pangala et al. 2017). This process is expected to interact with climate and physiological controls on WUE and should be considered in future models.

The numerical formulation and hypotheses proposed above focus on SPA interactions that have been sufficiently well described to yield predictions that could be used to address a need for land prioritization tools for natural or engineered climate solutions (Griscom et al. 2017; Schlesinger and Amundson 2018). We recognize that our proposed approach would require further validation for dynamic variables that are difficult to monitor, such as interannual variation in the structure and function of plant and microbial communities, before practical application. Future research stands to improve prediction and ability to manage ecosystems for climate change mitiation by considering a hierarchical framework that constrains dynamic SPA interactions within the well-defined boundaries of slow-changing landscape properties and evolutionarily determined resource use tradeoffs. Such an approach would address at least three challenges for climate change mitigation. First, it would improve landscape-level planning to enhance carbon sequestration, a function of primary productivity and organic matter stabilization, while optimizing the use of limiting water and nutrients. Second, it would allow for improved prediction of changes in radiative and water balances, both of which are affected by land cover, species composition, and surface albedo. Third, it would improve our ability to estimate and perhaps reduce the risk of catasthropic disturbance, such as fires, through conservation and management of carbon-rich drought-prone landscapes. We hope that the ideas discussed here will stimulate new efforts in the spatiotemporal scaling domain of SPA research to test theories and improve applied knowledge toward concerted action for climate change mitigation.

Acknowledgements Some of the data and ideas used in this synthesis were developed based on funding by the National Science Foundation Plant Biotic Interactions 1758947, Convergence Accelerator Pilot 1939511, and Atmospheric and Geospace Sciences 1602958 programs. We are thankful for comments provided by two anonymous reviewers and members of the Soil-PlantAtmosphere Research Laboratory and Institute of Ecology \& Evolution at the University of Oregon, which helped improve this review. 


\section{References}

Almond P, Roering J, Hales TC (2007) Using soil residence time to delineate spatial and temporal patterns of transient landscape response. J Geophys Res 112:F03S17. https://doi. org/10.1029/2006JF000568

Amundson R, Berhe AA, Hopmans JW et al (2015) Soil science. Soil and human security in the 21 st century. Science 348 : 1261071. https://doi.org/10.1126/science.1261071

Asner GP, Brodrick PG, Anderson CB et al (2016a) Progressive forest canopy water loss during the 2012-2015 California drought. Proc Natl Acad Sci U S A 113:E249-E255. https://doi.org/10.1073/pnas.1523397113

Asner GP, Knapp DE, Anderson CB et al (2016b) Large-scale climatic and geophysical controls on the leaf economics spectrum. Proc Natl Acad Sci 12:E4043-E4051. https://doi. org/10.1073/pnas.1604863113

Averill C, Bhatnagar JM, Dietze MC et al (2019) Global imprint of mycorrhizal fungi on whole-plant nutrient economics. Proc Natl Acad Sci U S A. https://doi.org/10.1073 /pnas. 1906655116

Baldocchi D (2008) "Breathing" of the terrestrial biosphere: lessons learned from a global network of carbon dioxide flux measurement systems. Aust J Bot 56:1-26

Baldocchi D (2014) Biogeochemistry: managing land and climate. Nat Clim Chang 4:330-331. https://doi.org/10.1038 /nclimate2221

Baldocchi D, Peñuelas J (2019) The physics and ecology of mining carbon dioxide from the atmosphere by ecosystems. Glob Chang Biol 25:1191-1197. https://doi.org/10.1111 /gcb.14559

Baldocchi D, Chu H, Reichstein M (2018) Inter-annual variability of net and gross ecosystem carbon fluxes: a review. Agric For Meteorol 249:520-533. https://doi.org/10.1016/J. AGRFORMET.2017.05.015

Baldocchi D, Dralle D, Jiang C, Ryu Y (2019) How much water is evaporated across California? A multiyear assessment using a biophysical model forced with satellite remote sensing data. Water Resour Res 55:2722-2741. https://doi.org/10.1029 /2018WR023884

Bauters M, Verbeeck H, Rütting T et al (2019) Contrasting nitrogen fluxes in African tropical forests of the Congo Basin. Ecol Monogr 89:e01342. https://doi.org/10.1002/ecm.1342

Beer C, Reichstein M, Tomelleri E et al (2010) Terrestrial gross carbon dioxide uptake: global distribution and covariation with climate. Science 329:834-838. https://doi.org/10.1126 /science.1184984

Berhe AA, Barnes RT, Six J, Marín-Spiotta E (2018) Role of soil erosion in biogeochemical cycling of essential elements: carbon, nitrogen, and phosphorus. Annu Rev Earth Planet Sci 46:521-548. https://doi.org/10.1146/annurev-earth082517-010018

Bingham MA, Simard S (2012) Ectomycorrhizal networks of seudotsuga menziesii var. glauca trees facilitate establishment of conspecific seedlings under drought. Ecosystems 15:188199

Bomfim B, Silva LCR, Doane TA, Horwath WR (2019) Interactive effects of land-use change and topography on asymbiotic nitrogen fixation in the Brazilian Atlantic
Forest. Biogeochemistry 142:137-153. https://doi. org/10.1007/s10533-018-0525-Z

Bonan G (2015) Surface energy fluxes, third. Cambridge, UK

Bonan GB, Williams M, Fisher RA, Oleson KW (2014) Modeling stomatal conductance in the earth system: linking leaf wateruse efficiency and water transport along the soil-plant-atmosphere continuum. Geosci Model Dev 7:2193-2222. https://doi.org/10.5194/gmd-7-2193-2014

Boyce CK, Lee J-E (2010) An exceptional role for flowering plant physiology in the expansion of tropical rainforests and biodiversity

Brantley SL, Eissenstat DM, Marshall JA et al (2017) Reviews and syntheses: on the roles trees play in building and plumbing the critical zone. Biogeosciences 145194:5115-5142. https://doi.org/10.5194/bg-14-5115-2017

Brice M, Cazelles K, Legendre P, Fortin M (2019) Disturbances amplify tree community responses to climate change in the temperate-boreal ecotone. Glob Ecol Biogeogr Geb.12971. doi: https://doi.org/10.1111/geb.12971

Brown JH, Gillooly JF, Allen AP et al (2004) Toward a metabolic theory of ecology. Ecology 85:1771-1789. https://doi. org/10.1890/03-9000

Bucher SF, Auerswald K, Tautenhahn S et al (2016) Inter- and intraspecific variation in stomatal pore area index along elevational gradients and its relation to leaf functional traits. Plant Ecol 217:229-240. https://doi.org/10.1007/s11258016-0564-2

Buzzard V, Michaletz ST, Deng Y et al (2019) Continental scale structuring of forest and soil diversity via functional traits. Nat Ecol Evol 3:1298-1308. https://doi.org/10.1038/s41559019-0954-7

Chen D-X, Coughenour MB (2004) Photosynthesis, transpiration, and primary productivity: scaling up from leaves to canopies and regions using process models and remotely sensed data. Global Biogeochem cycles 18:n/a-n/a. doi: https://doi. org/10.1029/2002GB001979

Coenders-Gerrits AMJ, van der Ent RJ, Bogaard TA et al (2014) Uncertainties in transpiration estimates. Nature 506:E1-E2. https://doi.org/10.1038/nature12925

Correa-Díaz A, Silva LCR, Horwath WR et al (2019) Linking remote sensing and dendrochronology to quantify climateinduced shifts in high-elevation forests over space and time. $\mathrm{J}$ Geophys Res Biogeosci 124:JG004687. https://doi. org/10.1029/2018JG004687

Creed IF, Spargo AT, Jones JA et al (2014) Changing forest water yields in response to climate warming: results from long-term experimental watershed sites across North America. Glob Chang Biol 20:3191-3208. https://doi.org/10.1111 /gcb. 12615

Crowther TW, Todd-Brown KEO, Rowe CW et al (2016) Quantifying global soil carbon losses in response to warming. Nature 540:104-108. https://doi.org/10.1038 /nature20150

Davis EL, Gedalof Z (2018) Limited prospects for future alpine treeline advance in the Canadian Rocky Mountains. Glob Chang Biol. https://doi.org/10.1111/gcb.14338

Delgado-Baquerizo M, Oliverio AM, Brewer TE et al (2018) A global atlas of the dominant bacteria found in soil. Science 359:320-325. https://doi.org/10.1126/science.aap9516

Dietrich R, Bell FW, Silva LCR et al (2016) Climatic sensitivity, water-use efficiency, and growth decline in boreal jack pine 
(Pinus banksiana) forests in northern Ontario. J Geophys Res Biogeosci 121:2761-2774. https://doi.org/10.1002/2016 JG003440

Doetterl S, Berhe AA, Arnold C et al (2018) Links among warming, carbon and microbial dynamics mediated by soil mineral weathering. Nat Geosci 11:589-593. https://doi. org/10.1038/s41561-018-0168-7

Earles JM, Sperling O, Silva LCR et al (2016) Bark water uptake promotes localized hydraulic recovery in coastal redwood crown. Plant Cell Environ 39:320-328. https://doi. org/10.1111/pce.12612

Eller CB, Lima AL, Oliveira RS (2013) Foliar uptake of fog water and transport belowground alleviates drought effects in the cloud forest tree species, Drimys brasiliensis (Winteraceae). New Phytol 199:151-162. https://doi.org/10.1111 /nph.12248

Elser JJ, Fagan WF, Kerkhoff AJ et al (2010) Biological stoichiometry of plant production: metabolism, scaling and ecological response to global change. New Phytol 186:593-608. https://doi.org/10.1111/j.1469-8137.2010.03214.x

Enquist BJ (2002) Universal scaling in tree and vascular plant allometry: toward a general quantitative theory linking plant form and function from cells to ecosystems. Tree Physiol 22: 1045-1064. https://doi.org/10.1093/treephys/22.15-16.1045

Enquist BJ, Norberg J, Bonser SP et al (2015) Scaling from traits to ecosystems: developing a general trait driver theory via integrating trait-based and metabolic scaling theories. Adv Ecol Res 52:249-318

Enquist BJ, Bentley LP, Shenkin A et al (2017) Assessing traitbased scaling theory in tropical forests spanning a broad temperature gradient. Glob Ecol Biogeogr. https://doi. org/10.1111/geb.12645

Estes L, Elsen PR, Treuer T et al (2018) The spatial and temporal domains of modern ecology. Nat Ecol Evol 2:819-826. https://doi.org/10.1038/s41559-018-0524-4

Evaristo J, Jasechko S, McDonnell JJ (2015) Global separation of plant transpiration from groundwater and streamflow. Nature 525:91-94. https://doi.org/10.1038/nature14983

Farnsworth KD, Albantakis L, Caruso T (2017) Unifying concepts of biological function from molecules to ecosystems. Oikos 126:1367-1376. https://doi.org/10.1111/oik.04171

Farquhar G, Richards R (1984) Isotopic composition of plant carbon correlates with water-use efficiency of wheat genotypes. Funct Plant Biol 11:539-552

Fellbaum CR, Mensah JA, Cloos AJ et al (2014) Fungal nutrient allocation in common mycorrhizal networks is regulated by the carbon source strength of individual host plants. New Phytol 203:646-656. https://doi.org/10.1111/nph.12827

Ferlian O, Biere A, Bonfante P et al (2018) Growing research networks on mycorrhizae for mutual benefits. Trends Plant Sci 23:975-984. https://doi.org/10.1016/J. TPLANTS.2018.08.008

Fine PVA (2015) Ecological and evolutionary drivers of geographic variation in species diversity. Annu Rev Ecol Evol Syst 46: 369-392. https://doi.org/10.1146/annurev-ecolsys-112414054102

Folke C, Carpenter S, Walker B et al (2004) Regime shifts, resilience, and biodiversity in ecosystem management. Annu Rev Ecol Evol Syst 35:557-581. https://doi. org/10.1146/annurev.ecolsys.35.021103.105711
Franco AC, Rossatto DR, Silva LCR, Ferreira CS (2014) Cerrado vegetation and global change: the role of functional types, resource availability and disturbance in regulating plant community responses to rising $\mathrm{CO}_{2}$ levels and climate warming. Theor Exp Plant Physiol 26:19-38. https://doi.org/10.1007 /s40626-014-0002-6

Franklin JF, Norman Johnson K (2014) Lessons in policy implementation from experiences with the northwest Forest plan, USA. Biodivers Conserv 23:3607-3613. https://doi. org/10.1007/s10531-014-0789-0

Giguère-Croteau C, Boucher É, Bergeron Y et al (2019) North America's oldest boreal trees are more efficient water users due to increased $\left[\mathrm{CO}_{2}\right]$, but do not grow faster. Proc Natl Acad Sci 116:2749-2754. https://doi.org/10.1073 /PNAS.1816686116

Gilbert L, Johnson D (2017) Plant-plant communication through common Mycorrhizal networks. Adv Bot Res 82:83-97. https://doi.org/10.1016/BS.ABR.2016.09.001

Gorzelak MA, Asay AK, Pickles BJ, Simard SW (2015) Interplant communication through mycorrhizal networks mediates complex adaptive behaviour in plant communities. AoB Plants 7:2041-2851

Gómez-Guerrero A, Silva LCR, Barrera-Reyes M, Kishchuk B (2013) Growth decline and divergent tree ring isotopic composition $(\delta 13 \mathrm{C}$ and $\delta 18 \mathrm{O})$ contradict predictions of $\mathrm{CO} 2$ stimulation in high altitudinal forests. Global Change Biology 19(6):1748-1758

Griscom BW, Adams J, Ellis PW et al (2017) Natural climate solutions. Proc Natl Acad Sci U S A 114:11645-11650. https://doi.org/10.1073/pnas.1710465114

Gunderson LH, Holling CS (2002) Panarchy: understanding transformations in human and natural systems. Island Press

Gunderson L, Cosens BA, Chaffin BC et al (2017) Regime shifts and panarchies in regional scale social-ecological water systems. Ecol Soc 22:art31. https://doi.org/10.5751/ES-08879220131

Hallema DW, Sun G, Caldwell PV et al (2018) Burned forests impact water supplies. Nat Commun 9:1307. https://doi. org/10.1038/s41467-018-03735-6

Harrison S, Damschen E, Fernandez-Going B et al (2015) Plant communities on infertile soils are less sensitive to climate change. Ann Bot 116:1017-1022. https://doi.org/10.1093 /aob/mcu230

Harrison SP, Bartlein PJ, Prentice IC (2016) What have we learnt from palaeoclimate simulations? J Quat Sci 31:363-385. https://doi.org/10.1002/jqs.2842

Hastings A, Abbott KC, Cuddington K et al (2018) Transient phenomena in ecology. Science 361:eaat6412. https://doi. org/10.1126/science.aat6412

Hayes JL, Riebe CS, Holbrook WS et al (2019) Porosity production in weathered rock: where volumetric strain dominates over chemical mass loss. Sci Adv 5:eaao0834. https://doi. org/10.1126/sciadv.aao0834

Hazard C, Johnson D (2018) Does genotypic and species diversity of mycorrhizal plants and fungi affect ecosystem function? New Phytol. https://doi.org/10.1111/nph.15010

Heaton LLM, López E, Maini PK et al (2010) Growth-induced mass flows in fungal networks. Proc R Soc Lond B Biol Sci 277:3265-3274

Heaton LLM, López E, Maini PK et al (2012) Advection, diffusion, and delivery over a network. Phys Rev E Stat Nonlinear 
Soft Matter Phys 86:021905. https://doi.org/10.1103 /PhysRevE.86.021905

Higgins SI (2017) Ecosystem assembly: a Mission for terrestrial earth system science. Ecosystems 20:69-77. https://doi. org/10.1007/s10021-016-0054-3

Hinsinger P, Marschner P (2006) Rhizosphere-perspectives and challenges - a tribute to Lorenz Hiltner 12-17 September 2004-Munich, Germany. Plant Soil 283:vii-viii. doi: https://doi.org/10.1007/s11104-006-0057-5

Hoffmann WA, Geiger EL, Gotsch SG et al (2012) Ecological thresholds at the savanna-forest boundary: how plant traits, resources and fire govern the distribution of tropical biomes. Ecol Lett 15:759-768. https://doi.org/10.1111/j.14610248.2012.01789.x

Jasechko S, Sharp ZD, Gibson JJ et al (2013) Terrestrial water fluxes dominated by transpiration. Nature 496:347-350. https://doi.org/10.1038/nature11983

Jerszurki D, Couvreur V, Maxwell T et al (2017) Impact of root growth and hydraulic conductance on canopy carbon-water relations of young walnut trees (Juglans regia L.) under drought. Sci Hortic (Amsterdam) 226:342-352. https://doi. org/10.1016/J.SCIENTA.2017.08.051

Johnstone JA, Dawson TE (2010) Climatic context and ecological implications of summer fog decline in the coast redwood region. Proc Natl Acad Sci U S A 107:4533-4538. https://doi.org/10.1073/pnas.0915062107

Johnstone JA, Roden JS, Dawson TE (2013) Oxygen and carbon stable isotopes in coast redwood tree rings respond to spring and summer climate signals. J Geophys Res Biogeosci 118: 1438-1450. https://doi.org/10.1002/jgrg.20111

Joosten H (2015) Current soil carbon loss and land degradation globally: where are the hotspots and why there? Soil Carbon Sci Manag Policy Mult Benefits 71:224-234

Kapoor V, Gelhar LW, Miralles-Wilhelm F (1997) Bimolecular second-order reactions in spatially varying flows: segregation induced scale-dependent transformation rates. Water Resour Res 33:527-536. https://doi.org/10.1029/96WR03687

Kempes CP, Koehl MAR, West GB (2019) The scales that limit: the physical boundaries of evolution. Front Ecol Evol. https://doi.org/10.3389/fevo.2019.00242

Kiers ET, Duhamel M, Beesetty Y, et al (2011) Reciprocal rewards stabilize cooperation in the Mycorrhizal Symbiosis. Science (80- ) 333:880-882

Körner C (2012) Alpine Treelines. Springer, Basel

Kröber W, Plath I, Heklau H, Bruelheide H (2015) Relating stomatal conductance to leaf functional traits. J Vis Exp. https://doi.org/10.3791/52738

Ladd B, Peri PL, Pepper DA et al (2014) Carbon isotopic signatures of soil organic matter correlate with leaf area index across woody biomes. J Ecol 102:1606-1611. https://doi. org/10.1111/1365-2745.12309

Lago ME, Miralles-Wilhelm F, Mahmoudi M, Engel V (2010) Numerical modeling of the effects of water flow, sediment transport and vegetation growth on the spatiotemporal patterning of the ridge and slough landscape of the Everglades wetland. Adv Water Resour 33:1268-1278. https://doi. org/10.1016/j.advwatres.2010.07.009

Lambers H, Bultynck L, Zhu Y-G (2007) Marschner reviews: a new initiative in delivering cutting-edge science in soil-plant interactions. Plant Soil 300:1-7. https://doi.org/10.1007 /s11104-007-9259-8
Lambers H, Raven JA, Shaver GR, Smith SE (2008) Plant nutrient-acquisition strategies change with soil age. Trends Ecol Evol 23:95-103. https://doi.org/10.1016/j. tree.2007.10.008

Lambers H, Martinoia E, Renton M (2015) Plant adaptations to severely phosphorus-impoverished soils. Curr Opin Plant Biol 25:23-31. https://doi.org/10.1016/j.pbi.2015.04.002

Lambers H, Albornoz F, Kotula L et al (2018) How belowground interactions contribute to the coexistence of mycorrhizal and non-mycorrhizal species in severely phosphorusimpoverished hyperdiverse ecosystems. Plant Soil 424:1133. https://doi.org/10.1007/s11104-017-3427-2

Le Quéré C, Andrew RM, Friedlingstein P et al (2018) Global carbon budget 2018. Earth Syst Sci Data 10:2141-2194. https://doi.org/10.5194/essd-10-2141-2018

Levin S (1992) The problem of pattern and scale in ecology. Ecology 73:1943-1967

Liles GC, Maxwell TM, Silva LCR et al (2019) Two decades of experimental manipulation reveal potential for enhanced biomass accumulation and water use efficiency in ponderosa pine plantations across climate gradients. J Geophys Res Biogeosci 124:2321-2334. https://doi.org/10.1029/2019 jg005183

Lindeburg KS, Almond P, Roering JJ, Chadwick OA (2013) Pathways of soil genesis in the coast range of Oregon, USA. Plant Soil 367:57-75. https://doi.org/10.1007/s11104012-1566-z

Louca S, Polz MF, Mazel F et al (2018) Function and functional redundancy in microbial systems. Nat Ecol Evol 2:936-943. https://doi.org/10.1038/s41559-018-0519-1

Lützow MV, Kögel-Knabner I, Ekschmitt K et al (2006) Stabilization of organic matter in temperate soils : mechanisms and their relevance under different soil conditions - a review. Eur J Soil Sci 57:426-445

Mankin JS, Smerdon JE, Cook BI, et al (2017) The curious case of projected 21st-century drying but greening in the American West. J Clim JCLI-D-17-0213.1. doi: https://doi.org/10.1175 /JCLI-D-17-0213.1

Marshall JD, Brooks JR, Lajtha K (2007) Sources of variation in stable isotopes of plants. In: Lajtha K, Michener R (eds) Stable isotopes in ecology and environmental science

Maxwell TM, Silva LCR, Horwath WR (2014) Using multielement isotopic analysis to decipher drought impacts and adaptive management in ancient agricultural systems: fig. 1. Proc Natl Acad Sci 111:E4807-E4808. https://doi.org/10.1073 /pnas.1417618111

Maxwell TM, Silva LCR, Horwath WR (2018a) Integrating effects of species composition and soil properties to predict shifts in montane forest carbon-water relations. Proc Natl Acad Sci 115:201718864. https://doi.org/10.1073 /PNAS.1718864115

Maxwell TM, Silva LCR, Horwath WR (2018b) Predictable oxygen isotope exchange between plant lipids and environmental water: implications for ecosystem water balance reconstruction. J Geophys Res Biogeosci 123:2941-2954. https://doi. org/10.1029/2018JG004553

Medlyn BE, Zaehle S, De Kauwe MG, et al (2015) Using ecosystem experiments to improve vegetation models. 5:528-534. doi: https://doi.org/10.1038/NCLIMATE2621 
Medlyn BE, De Kauwe MG, Lin Y-S et al (2017) How do leaf and ecosystem measures of water-use efficiency compare? New Phytol 216:758-770. https://doi.org/10.1111/nph.14626

Messier J, Violle C, Enquist BJ et al (2018) Similarities and differences in intrapopulation trait correlations of cooccurring tree species: consistent water-use relationships amid widely different correlation patterns. Am J Bot 105: 1477-1490. https://doi.org/10.1002/ajb2.1146

Michaletz ST, Kerkhoff AJ, Enquist BJ (2018) Drivers of terrestrial plant production across broad geographical gradients. Glob Ecol Biogeogr 27:166-174. https://doi.org/10.1111 /geb.12685

Mikutta R, Kleber M, Torn MS, Jahn R (2006) Stabilization of soil organic matter: association with minerals or chemical recalcitrance? Biogeochemistry 77:25-56. https://doi.org/10.1007 /s10533-005-0712-6

Miralles-Wilhelm F (2016) Development and application of integrative modeling tools in support of food-energy-water nexus planning - a research agenda. J Environ Stud Sci 6:3-10. https://doi.org/10.1007/s13412-016-0361-1

Morford SL, Houlton BZ, Dahlgren RA (2016) Geochemical and tectonic uplift controls on rock nitrogen inputs across terrestrial ecosystems. Glob Biogeochem Cycles 30:333-349. https://doi.org/10.1002/2015GB005283

Myers SS, Zanobetti A, Kloog I et al (2014) Increasing $\mathrm{CO}_{2}$ threatens human nutrition. Nature 510:139-142. https://doi. org/10.1038/nature13179

Nolan C, Overpeck JT, Allen JRM et al (2018) Past and future global transformation of terrestrial ecosystems under climate change. Science 361:920-923. https://doi.org/10.1126 /science.aan5360

Novák V (2012) Movement of water in soil during evaporation. In: Evapotranspiration in the Soil-Plant-Atmosphere System. Springer, pp 59-83

O'Geen AT, Safeeq M, Wagenbrenner J et al (2018) Southern sierra critical zone observatory and kings river experimental watersheds: a synthesis of measurements, new insights, and future directions. Vadose Zo J. https://doi.org/10.2136 /vzj2018.04.0081

Ogle K, Barber JJ, Barron-Gafford GA et al (2015) Quantifying ecological memory in plant and ecosystem processes. Ecol Lett 18:221-235. https://doi.org/10.1111/ele.12399

Oliveira RS, Dawson TE, Burgess SSO (2005) Evidence for direct water absorption by the shoot of the desiccation-tolerant plant Vellozia flavicans in the savannas of Central Brazil. J Trop Ecol 21:585-588. https://doi.org/10.1017 /S0266467405002658

Or D, Wraith JM (2002) Soil water content and water potential relationships. In: Handbook of soil sciences: properties and processes. CRC Press, New York, pp 49-84

Paiva AO, Silva LCR, Haridasan M (2016) Productivityefficiency tradeoffs in tropical gallery forest-savanna transitions: linking plant and soil processes through litter input and composition. Plant Ecol 216:775-787. https://doi. org/10.1007/s11258-015-0466-8

Pangala SR, Enrich-Prast A, Basso LS et al (2017) Large emissions from floodplain trees close the Amazon methane budget. Nature 14:230-234. https://doi.org/10.1038/nature24639

Perry TD, Jones JA (2017) Summer streamflow deficits from regenerating Douglas-fir forest in the Pacific northwest,
USA. Ecohydrology 10:e1790. https://doi.org/10.1002 /eco. 1790

Philip JR (1966) Plant water relations: some physical aspects. Annu Rev Plant Physiol 17:245-268. https://doi. org/10.1146/annurev.pp.17.060166.001333

Pietsch KA, Ogle K, Cornelissen JHC et al (2014) Global relationship of wood and leaf litter decomposability: the role of functional traits within and across plant organs. Glob Ecol Biogeogr 23:1046-1057. https://doi.org/10.1111/geb.12172

Powell JR, Riley RC, Cornwell W (2017) Relationships between mycorrhizal type and leaf flammability in the Australian flora. Pedobiologia (Jena) 65:43-49. https://doi.org/10.1016 /J.PEDOBI.2017.07.001

Qiao Y, Miao S, Silva LCR, Horwath WR (2014) Understory species regulate litter decomposition and accumulation of $\mathrm{C}$ and $\mathrm{N}$ in forest soils: a long-term dual-isotope experiment. For Ecol Manag 329:318-327. https://doi.org/10.1016/j. foreco.2014.04.025

Rasmussen C, Tabor NJ (2007) Applying a quantitative Pedogenic energy model across a range of environmental gradients. Soil Sci Soc Am J 71:1719. https://doi.org/10.2136 /sssaj2007.0051

Raven JA, Lambers H, Smith SE, Westoby M (2018) Costs of acquiring phosphorus by vascular land plants: patterns and implications for plant coexistence. New Phytol 217:1420 1427. https://doi.org/10.1111/nph.14967

Reich PB, Hobbie SE, Lee TD (2014) Plant growth enhancement by elevated $\mathrm{CO}_{2}$ eliminated by joint water and nitrogen limitation. Nat Geosci 7:920-924. https://doi.org/10.1038 /ngeo2284

Roering JJ, Perron JT, Kirchner JW (2007) Functional relationships between denudation and hillslope form and relief. Earth Planet Sci Lett 264:245-258. https://doi.org/10.1016/J. EPSL.2007.09.035

Rossatto DR, Silva LCR, Villalobos-Vega R et al (2012) Depth of water uptake in woody plants relates to groundwater level and vegetation structure along a topographic gradient in a neotropical savanna. Environ Exp Bot 77:259-266. https://doi.org/10.1016/j.envexpbot.2011.11.025

Sachse D, Billault I, Bowen GJ et al (2012) Molecular Paleohydrology: interpreting the hydrogen-isotopic composition of lipid biomarkers from photosynthesizing organisms. Annu Rev Earth Planet Sci 40:221-249. https://doi. org/10.1146/annurev-earth-042711-105535

Saha AK, Setegn SG (2015) Ecohydrology: understanding and maintaining ecosystem services for IWRM. In: Sustainability of integrated water resources management. Springer International Publishing, Cham, pp 121-145

Saha AK, da Silveira O'Reilly Sternberg L, Ross MS, MirallesWilhelm F (2010) Water source utilization and foliar nutrient status differs between upland and flooded plant communities in wetland tree islands. Wetl Ecol Manag 18:343-355. https://doi.org/10.1007/s11273-010-9175-1

Salzer MW, Hughes MK, Bunn AG, Kipfmueller KF (2009) Recent unprecedented tree-ring growth in bristlecone pine at the highest elevations and possible causes. Proc Natl Acad Sci U S A 106:20348-20353

Schlesinger WH, Amundson R (2018) Managing for soil carbon sequestration: Let's get realistic. Glob Chang Biol GCB.14478. doi: https://doi.org/10.1111/gcb.14478 
Schlesinger WH, Jasechko S (2014) Transpiration in the global water cycle. Agric For Meteorol 189-190:115-117. https://doi.org/10.1016/j.agrformet.2014.01.011

Schmidt M, Torn MS, Abiven S et al (2011) Persistence of soil organic matter as an ecosystem property. Nature 478:49-56. https://doi.org/10.1038/nature10386

Seitz S, Goebes P, Puerta VL et al (2019) Conservation tillage and organic farming reduce soil erosion. Agron Sustain Dev 39:4. https://doi.org/10.1007/s13593-018-0545-Z

Shi C, Silva LCR, Zhang H et al (2015) Climate warming alters nitrogen dynamics and total non-structural carbohydrate accumulations of perennial herbs of distinctive functional groups during the plant senescence in autumn in an alpine meadow of the Tibetan plateau, China. Agric For Meteorol 200:21-29. https://doi.org/10.1016/j.agrformet.2014.09.006

Silva LCR, Anand M (2013) Historical links and new frontiers in the study of forest-atmosphere interactions. Community Ecol 14:208-218. https://doi.org/10.1556/ComEc.14.2013.2.11

Silva LCR, Lambers H (2018) Soil-plant-atmosphere interactions: ecological and biogeographical considerations for climatechange research. In: Horwath W, Kuzyakov Y (eds) Climate change impacts on soil processes and ecosystem properties. Elsevier Academic Press, p 625

Silva LCR, Corrêa R, Doane TA et al (2013a) Unprecedented carbon accumulation in mined soils: the synergistic effect of resource input and plant species invasion. Ecol Appl 23: 1345-1356. https://doi.org/10.1890/12-1957.1

Silva LCR, Hoffmann WA, Rossatto DR et al (2013b) Can savannas become forests? A coupled analysis of nutrient stocks and fire thresholds in Central Brazil. Plant Soil 373:829-842. https://doi.org/10.1007/s11104-013-1822-x

Silva LCR, Salamanca-Jimenez A, Doane TA, Horwath WR (2015a) Carbon dioxide level and form of soil nitrogen regulate assimilation of atmospheric ammonia in young trees. Sci Rep 5:13141. https://doi.org/10.1038/srep13141

Silva LCR, Doane TA, Corrêa RS et al (2015b) Iron-mediated stabilization of soil carbon amplifies the benefits of ecological restoration in degraded lands. Ecol Appl 25:1226-1234. https://doi.org/10.1890/14-2151.1

Silva LCR, Pedroso G, Doane TA et al (2015c) Beyond the cellulose: oxygen isotope composition of plant lipids as a proxy for terrestrial water balance. Geochemical Perspect Lett 1:33-42

Silva LCR, Sun G, Zhu-Barker X et al (2016) Tree growth acceleration and expansion of alpine forests: the synergistic effect of atmospheric and edaphic change. Sci Adv 2:e1501302

Simard SW (2009) The foundational role of mycorrhizal networks in self-organization of interior Douglas-fir forests. For Ecol Manag 258:S95-S107. https://doi.org/10.1016/j. foreco.2009.05.001

Simard SW, Beiler KJ, Bingham MA et al (2012) Mycorrhizal networks: mechanisms, ecology and modelling. Fungal Biol Rev 26:39-60. https://doi.org/10.1016/j.fbr.2012.01.001

Simard S, Asay A, Beiler K, et al (2015) Mycorrhizal networks: mechanisms, ecology and modelling. In: Mycorrhizal Networks. pp 133-176

Song YY, Simard SW, Carroll A et al (2015) Defoliation of interior Douglas-fir elicits carbon transfer and stress signalling to ponderosa pine neighbors through ectomycorrhizal networks. Sci Rep 5:8495. https://doi.org/10.1038/srep08495
Sperling O, Silva LCR, Tixier A et al (2017) Temperature gradients assist carbohydrate allocation within trees. Sci Rep 7: 3265. https://doi.org/10.1038/s41598-017-03608-w

Sprintsin M, Chen JM, Desai A, Gough CM (2012) Evaluation of leaf-to-canopy upscaling methodologies against carbon flux data in North America. J Geophys Res Biogeosci. https://doi. org/10.1029/2010JG001407

Stevens JT, Safford HD, Harrison S, Latimer AM (2015) Forest disturbance accelerates thermophilization of understory plant communities. J Ecol 103:1253-1263. https://doi.org/10.1111 /1365-2745.12426

Taylor LL, Banwart SA, Valdes PJ et al (2012) Evaluating the effects of terrestrial ecosystems, climate and carbon dioxide on weathering over geological time: a global-scale processbased approach. Philos Trans R Soc Lond Ser B Biol Sci 367: 565-582. https://doi.org/10.1098/rstb.2011.0251

Taylor TC, McMahon SM, Smith MN et al (2018) Isoprene emission structures tropical tree biogeography and community assembly responses to climate. New Phytol 220:435446. https://doi.org/10.1111/nph.15304

Terrer C, Vicca S, Hungate BA et al (2016) Mycorrhizal association as a primary control of the $\mathrm{CO}_{2}$ fertilization effect. Science 353:72-74. https://doi.org/10.1126/science.aaf4610

Terrer C, Vicca S, Stocker BD et al (2018) Ecosystem responses to elevated $\mathrm{CO}_{2}$ governed by plant-soil interactions and the cost of nitrogen acquisition. New Phytol 217:507-522. https://doi.org/10.1111/nph.14872

Terrer C, Jackson RB, Prentice IC et al (2019) Nitrogen and phosphorus constrain the $\mathrm{CO}_{2}$ fertilization of global plant biomass. Nat Clim Chang:1-6. https://doi.org/10.1038 /s41558-019-0545-2

Teste FP, Simard SW, Durall DM et al (2010) Net carbon transfer between Pseudotsuga menziesii var. glauca seedlings in the field is influenced by soil disturbance. J Ecol 98:429-439. https://doi.org/10.1111/j.1365-2745.2009.01624.x

Tharammal T, Bala G, Narayanappa D, Nemani R (2019) A review of the major drivers of the terrestrial carbon uptake: model-based assessments, consensus, and uncertainties. Environ Res Lett. https://doi.org/10.1088/1748-9326/ab3012

Tian F, Wigneron J-P, Ciais P et al (2018) Coupling of ecosystemscale plant water storage and leaf phenology observed by satellite. Nat Ecol Evol. https://doi.org/10.1038/s41559-0180630-3

Tuthorn M, Zech M, Ruppenthal M et al (2014) Oxygen isotope ratios $(18 \mathrm{O} / 16 \mathrm{O})$ of hemicellulose-derived sugar biomarkers in plants, soils and sediments as paleoclimate proxy II: insight from a climate transect study. Geochim Cosmochim Acta 126:624-634. https://doi.org/10.1016/j. gca.2013.11.002

Valentini R, Gamon JA, Field CB (1995) Ecosystem gas exchange in a California grassland: seasonal patterns and implications for scaling. Ecology 76:1940-1952. https://doi.org/10.2307 $/ 1940725$

van der Heijden MGA, Martin FM, Selosse M-A, Sanders IR (2015) Mycorrhizal ecology and evolution: the past, the present, and the future. New Phytol 205:1406-1423. https://doi.org/10.1111/nph.13288

Verhoeven E, Barthel M, Yu L et al (2019) Early season N2O emissions under variable water management in rice systems: source-partitioning emissions using isotope ratios along a 
depth profile. Biogeosciences 16:383-408. https://doi. org/10.5194/bg-16-383-2019

Vitousek PM, Chadwick OA (2013) Pedogenic thresholds and soil process domains in basalt-derived soils. Ecosystems 16: 1379-1395. https://doi.org/10.1007/s10021-013-9690-z

Ward BM, Wong CI, Novello VF et al (2019) Reconstruction of Holocene coupling between the South America monsoon system and local moisture variability from speleothem $\delta 18 \mathrm{O}$ and $87 \mathrm{Sr} / 86 \mathrm{Sr}$ records. Quat Sci Rev 210:51-63. https://doi.org/10.1016/J.QUASCIREV.2019.02.019

Weil RR, Brady NC (2016) The nature and properties of soils. Soil Sci Soc Am J 80:1428. https://doi.org/10.2136/sssaj2016.0005br

Weremijewicz J, da Sternberg LSLO, Janos DP (2016) Common mycorrhizal networks amplify competition by preferential mineral nutrient allocation to large host plants. New Phytol 212:461-471. https://doi.org/10.1111/nph.14041

West GB (2017) Scale : the universal laws of growth, innovation, sustainability, and the pace of life in organisms, cities, economies, and companies. New York, NY

Winsome T, Silva LCR, Scow KM et al (2017) Plant-microbe interactions regulate carbon and nitrogen accumulation in forest soils. For Ecol Manag 384:415-423. https://doi. org/10.1016/j.foreco.2016.10.036

Wortham BE, Wong CI, Silva LCR et al (2017) Assessing response of local moisture conditions in Central Brazil to variability in regional monsoon intensity using speleothem $87 \mathrm{Sr} / 86 \mathrm{Sr}$ values. Earth Planet Sci Lett 463:310-322. https://doi.org/10.1016/j.eps1.2017.01.034

Wright IJ, Reich PB, Westoby M et al (2004) The worldwide leaf economics spectrum. Nature 428:821-827

Zech M, Glaser B (2009) Compound-specific d18O analyses of neutral sugars in soils using gas chromatography-pyrolysisisotope ratio mass spectrometry: problems, possible solutions and a first application. Rapid Commun Mass Spectrom 23: 3522-3532
Zech M, Werner RA, Juchelka D et al (2012) Absence of oxygen isotope fractionation/exchange of (hemi-) cellulose derived sugars during litter decomposition. Org Geochem 42:14701475

Zech M, Mayr C, Tuthorn M et al (2014) Oxygen isotope ratios (180/16O) of hemicellulose-derived sugar biomarkers in plants, soils and sediments as paleoclimate proxy I: insight from a climate chamber experiment. Geochim Cosmochim Acta 126:614-623. https://doi.org/10.1016/j. gca.2013.10.048

Zemunik G, Turner BL, Lambers H, Laliberté E (2015) Diversity of plant nutrient-acquisition strategies increases during longterm ecosystem development. Nat Plants 1:15050. https://doi.org/10.1038/nplants.2015.50

Zemunik G, Turner BL, Lambers H, Laliberté E (2016) Increasing plant species diversity and extreme species turnover accompany declining soil fertility along a long-term chronosequence in a biodiversity hotspot. J Ecol 104:792-805. https://doi.org/10.1111/13652745.12546

Zhai L, Jiang J, DeAngelis D, da Silveira Lobo Sternberg L (2016) Prediction of plant vulnerability to salinity increase in a coastal ecosystem by stable isotope composition $(818 \mathrm{O})$ of plant stem water: a model study. Ecosystems 19:32-49. https://doi.org/10.1007/s10021-015-9916-3

Zhang K, Kimball JS, Nemani RR et al (2015) Vegetation greening and climate change promote multidecadal rises of global land evapotranspiration. Sci Rep 5:15956. https://doi. org/10.1038/srep 15956

Publisher's note Springer Nature remains neutral with regard to jurisdictional claims in published maps and institutional affiliations. 